\title{
Anmerkung zur Stabilität und chemischen Desinfektion von Viren
}

\author{
Stability and Chemical Disinfection of Viruses \\ F. v. Rheinbaben, M. H. Wolff
}

\begin{abstract}
Zusammenfassung:
Die Stabilität der Viren gegen chemische und physikalische Einflüsse ist unter natürlichen Bedingungen erheblich größer, als dies allgemein angenommen wird. Sie wird vor allem durch den Virusbau und durch das Material bestimmt, in dem das Virus vorliegt. Für den sinnvollen Einsatz von chemischen Desinfektionsmitteln zur Inaktivierung von Viren sind zusätzlich auch epidemiologische Kenntnisse und das Wissen über die chemische Wirkung der Mittel erforderlich.
\end{abstract}

Schlüsselwörter:

Chemische Desinfektionsmittel - viruzid - Virusinaktivierung - Virusresistenz - Umweltresisteriz

\begin{abstract}
Summary:
The stability of viruses against chemical or physical inactivation is much higher under natural conditions than generally expected. This is mainly determined by the construction of virus particles and the material which surrounds them. Furthermore the knowledge about the epidemiology of virus diseases and the mode of action of chemical disinfectants is necessary for the effective usage of virucidal disinfectants.
\end{abstract}

Keywords:

Chemical disinfectant - virucidal - virus inactivation - virus stability - environmental resistancy of viruses

\section{Einleitung}

Als Erregern von Infektionskrankheiten kommt den Viren eine sehr viel größere Bedeutung zu, als allgemein angenommen wird. Nach WHO-Schätzungen zählen $90 \%$ aller bekannten Infektionserreger zu den Viren; jeder zweite Patient mit einer Infektionskrankheit leidet an einer Virusinfektion. Die therapeutischen Möglichkeiten, z. B. durch Chemotherapeutika, sind auch heute noch sehr beschränkt; wirksame Gegenmaßnahmen haben daher zumeist prophylaktischen Charakter.

Neben der Schutzimpfung und der Expositionsprophylaxe durch Hygienemaßnahmen hat auch die Virusinaktivierung durch den Einsatz chemischer Desinfektionsmittel und -verfahren eine große Bedeutung. erlangt. Deren Anwendung ist heute längst nicht nur auf den Bereich der modernen Medizin und unmittelbar angrenzender Gebiete beschränkt.

Die Verhütung bzw. Bekämpfung von viralen Infektionen durch Desinfektionsmaßnahmen setzt jedoch in viel stärkerem Maße ein Wissen über Bau, Übertragungswege, Umweltresistenz und Verhalten gegenüber Desinfektionsmitteln voraus, als dies bei der Bekämpfung bakterieller Infektionen notwendig ist. Im Einzelfall ist auch die Kenntnis des vorliegenden Virus und dessen speziellen Eigenarten für die erfolgreiche Durchführung von Desinfektionsmaßnahmen angebracht. Der folgende Beitrag soll hier eine Einführung geben.

\section{Viren, Abgrenzung zu anderen Gruppen von Krankheitserregern}

Anders als Bakterien, die sich als echte, wenngleich einfach gebaute Zellen durch Zweiteilung vermehren, sind Viren stets obligate Zellparasiten und für ihre Replikation auf lebende Zellen angewiesen. Sie sind erheblich kleiner als Bakterien (20-200nm) und besitzen keinen eigenen Stoffwechsel:

Bakteriophagen unterscheiden. sich in der Wahl ihrer Wirtszellen (Bakterienzellen) und in einigen Besonderheiten ihres Replikationszyklus von „echten Viren”. Ihre unmittelbare medizinische Relevanz ist eher gering, wenn man von ihrer Bedeutung bei der Toxinproduktion von Bàkterien (z. B. Verotoxin) oder als Hilfsmittel der Diagnostik (Lysotypie) absieht. In der industriellen Biotechnologie oder der Lebensmittelveredlung, z. B. bei der Käseund Joghurt-Herstellung, haben sie als Störungsursache des Fermentationsprozesses eine erhebliche Bedeutung erlangt.

Rickettsien und Chlamydien, ebenfalls obligate Zellparasiten, wurden lange zu den Viren gezählt. Heute weiß man, daß sie einfacher gebaute bakterienähnliche Lebensformen sind.

Unkonventionelle Viren werden auch als Prionen oder Virinos bezeichnet und sind Erreger von Infektionskrankheiten, deren Natur noch weitestgehend im. dunkeln liegt. 
Die wohl revolutionärste Hypothese über ihren Bau disku. tiert sie als infektiöse Proteinmoleküle. Hierzu sei als Beispiel die Creutzfeldt-Jakob-Erkrankung des Menschen oder die bovine spongiforme Enzephalopathie (BSE) genannt.

Viroide sind demgegenüber infektiöse RNA-Moleküle. Ihre Existenz als Erreger von Pflanzenkrankheiten ist bewiesen. Auf ihre Stabilität und Desinfektion soll nicht weiter eingegangen werden.

\section{Bau und Vermehrung der Viren}

Viren bestehen im einfachsten Fall aus einer genetischen Information (DNS oder RNS), die in eine Proteinhülle ein- geschlossen ist (Abb. 1). Außerhalb ihrer Wirtszellen befinden sie sich in einem Grenzzustand zwischen belebter und unbelebter Materie, der am besten durch die dann mögliche Kristallisierbarkeit der Partikel zu veranschaulichen ist. Dieser auch als Aggregatbildung bezeichnete Vorgang hat für die Desinfektion von Viren eine große Bedeutung, da Viruspartikel im Inneren solcher Aggregate durch Desinfektionsmittel weit schwerer $\mathrm{zu}$ inaktivieren sind.

Innerhalb ihrer Wirtszelle sind dagegen zwei Verhaltensweisen möglich, die jeweils beide ein Extrem darstellen, wobei es sehr unterschiedliche Übergangsformen gibt. Einerseits kann nach Eindringen des Viruspartikels der wirtseigene Stoffwechsel völlig zum Erliegen kommen.

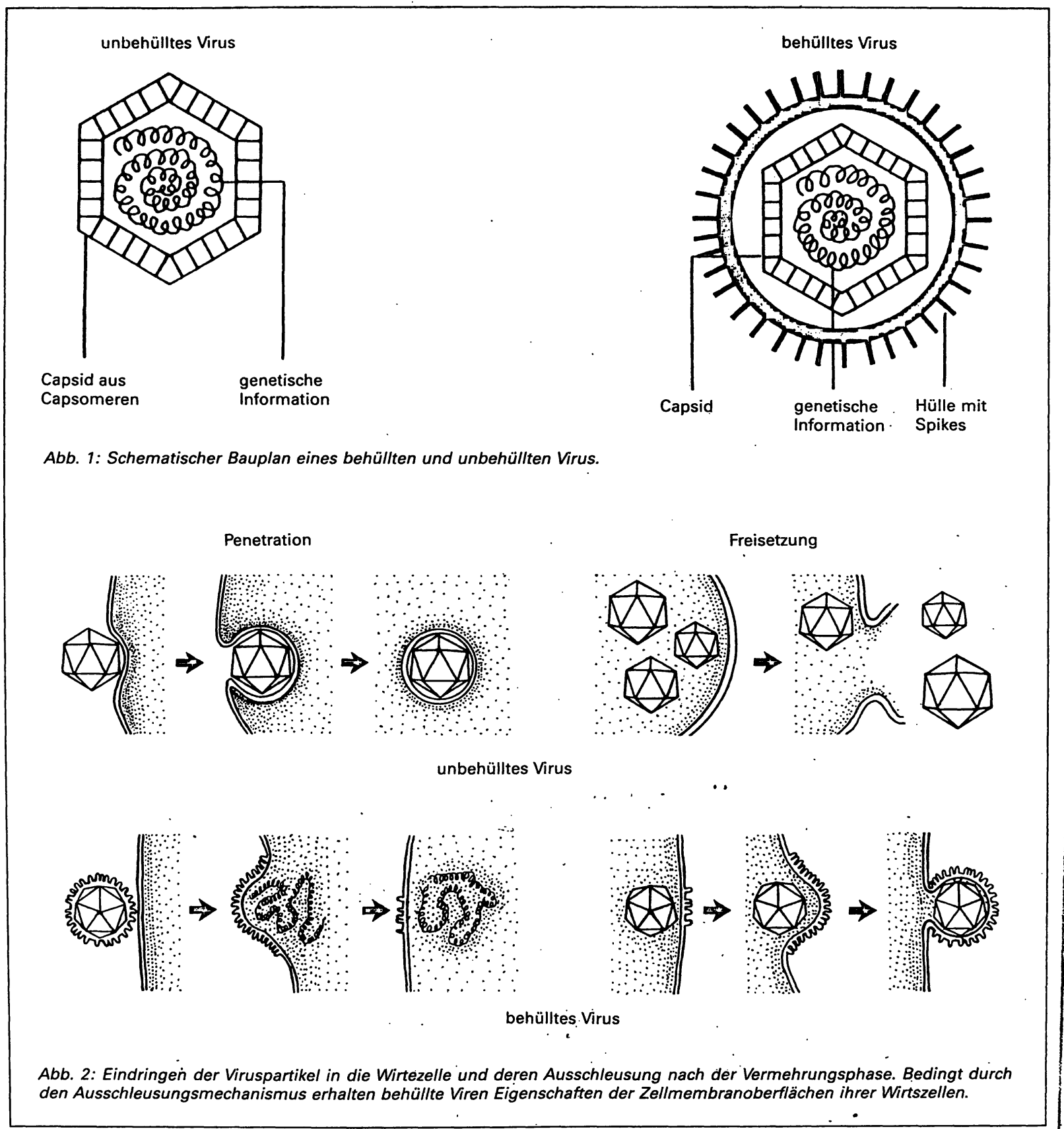


Die Zelle zerstört sich durch die Produktion von Virusproteinen und viraler DNS bzw. RNS, wobei komplette Viruspartikel zusammengebaut werden. Dabei kann eine einzige infizierte Zelle mehr als $10^{5}$ infektiöse Viruspartikel freisetzen.

Das andere Extrem ist der Einbau der genetischen Information des Virus in die zelleigene Erbinformation, aus dem eine lebenslang persistierende Infektion resultiert. Beispiel für die erste Alternative ist das Poliovirus. Die infizierte Persón scheidet während der akuten Phase große Mengen an Virus aus. Die Symptome der Krankheit werden durch den Ausfall zerstörter Zellen und durch körpereigene Abwehrreaktionen hervorgerufen. Der Rekonvaleszente ist später nicht nur immun, sondern auch virusfrei. Dagegen persistieren Viren der Herpesgruppe oder auch das HIV zeitlebens nach einer einmal durchgemachten Primärinfektion. In der Folge kommt es zu phasenweiser (latente persistierende Infektion mit zeitweiser Reaktivierung) bzw. zu permanenter Abgabe (chronisch aktive Infektion) von Viruspartikeln. Der Betreffende bleibt für andere daher immer potentiell infektiös.

\section{Lipophile Viren - hydrophile Viren}

Abhängig vom Mechanismus der Aus- bzw. Einschleusung in die Wirtszelle unterscheidet man behüllte und unbehüllte Viren (Abb. 1 u. 2). Unbehülite Viren bestehen, wie bereits erwähnt, aus einem oder mehreren DNSoder RNS-Molekülen und aus einer Proteinhülle (Capsid) die ihrerseits aus einzelnen, meist gleichartigen Eiweißmolekülen (Capsomeren) zusammengesetzt ist. Diese Viren werden zum Abschluß des Replikationszyklus durch Lysieren der Wirtszelle freigesetzt.

Die behüllten Viren haben dagegen eine oder mehrere zusätzliche Hüllen (Envelope), die dadurch entstehen, daß das Virus zum Ende seines Vermehrungszyklus durch Membranen der Wirtszelle "hindurchknospt" und so einen Teil der Membranoberfläche mitnimmt, in den es gleichsam verpackt wird. Die zusätzliche Hülle mit einem hohen Anteil von Membranlipiden verleiht dem Viruspartikel lipophile Eigenschaften; man spricht daher auch von lipophilen Viren. Der Anteil der Lipide und damit der Grad der Lipophilie kann jedoch in den einzelnen Virusgruppen beträchtlich schwanken.

Unbehüllte Viren sind demgegenüber meist hydrophil. Es gibt aber unter ihnen solche, die mit Lipiden reagieren und die daher eine Sonderstellung einnehmen. Nach dem Grad ihrer Lipophilie bietet sich daher die Einteilung der Viren in vier Gruppen an (Tab. 1).

\section{Umweltresistenz konventioneller Viren}

Unter anderem sind es die beiden Oberflächeneigenschaften „behüllt" und "unbehüllt”, die die Virusstabilität in der Umwelt beeinflussen: Unbehüllte Viren gelten insgesamt als umweltstabiler. Da es sich bei dieser Gruppe häufig um Erreger handelt, die durch Schmier- oder Kontaktinfektionen weitergegeben werden, ist ein Aufenthalt in der Umwelt außerhalb des Wirtskörpers in der Biologie dieser Viren durchaus, vorgesehen. Die Wahrscheinlichkeit einer Neuinfektion wird durch die hohe Umweltresistenz vergrößert. In Wasser und Abwasser beispielsweise können solche Viren ihre Infektiosität über viele Wochen beibehalten, ebenso in gekühltem Material (Kühischrank, $+4^{\circ} \mathrm{C}$ ). Bei bereits $-20^{\circ} \mathrm{C}$ tiefgekühlt bleiben viele Arten nahezu unbegrenzt infektiös.

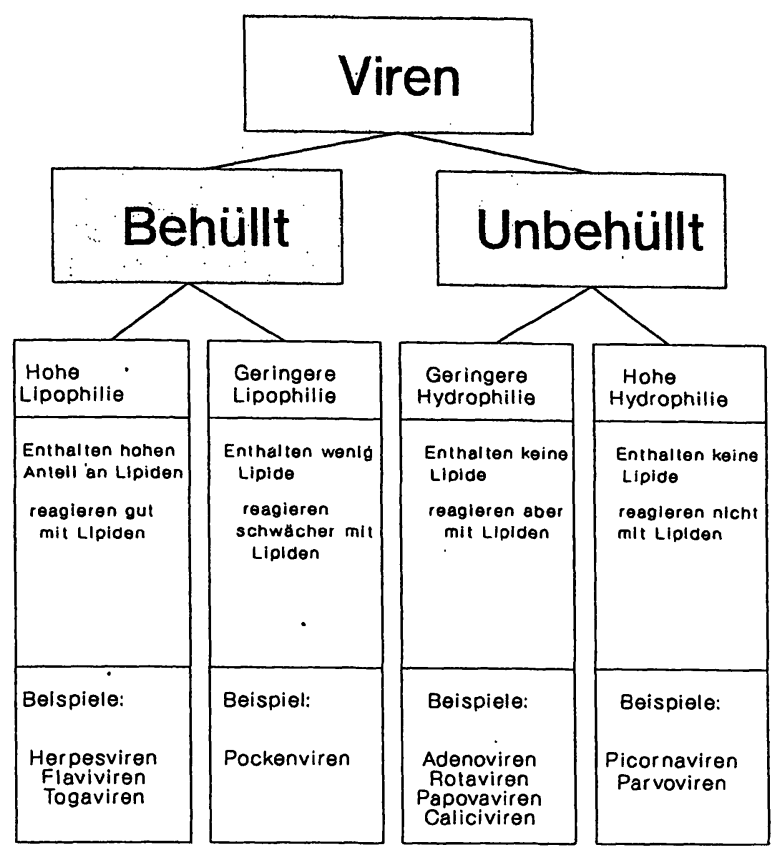

Tab. 1: Einteilung der Viren in Abhängigkeit vom Grad ihrer Lipophilie.

Behüllte Viren gelten dagegen als weniger umweltresistent. Häufig werden sie unter weitgehender Vermeidung eines Aufenthaltes in der Umwelt weitergegeben und nutzen natürliche. Infektionswege wie z. B. die sexuelle Übertragung oder die Übertragung durch Vektoren (Zecken, Mücken etc.). Aber auch durch den Umgang mit kontaminiertem Material, Kontakt mit Blut etc. ergibt sich eine Vielzahl zusätzlicher Übertragungsmöglichkeiten.

In bezug auf die Trockenstabilität verwischen sich allerdings die Unterschiede zwischen behüliten und unbehüllten Viren. Auch wenn hier für viele unbehüllte Viren eine höhere Stabilität festzustellen ist (wir konnten zeigen, daß manche unbehüllten Viren auf Arbeitsflächen über mehrere Wochen ihre Infektiösität beibehalten), so kann damit nicht gleichzeitig eine geringere Stabilität für behüllte Viren abgeleitet werden. Vor allem dann, wenn $V_{i}$ ruspartikel in ihrem natürlichen Milieu, z. B. in Blut, Serum, Gewebe, Biopsiematerial, Stuhl etc., vorliegen, kommt es zwar während des Eintrocknens zu beträchtlichen Aktivitätsverlusten, die verbleibenden Partikel, unabhängig ob behüllt oder unbehüllt, sind danach jedoch gegen weitere Inaktivierung geschützt und können über mehrere Wochen, ja sogar über viele Jahre infektiös bleiben.

Tabakblätter z. B., die 1882 als Muster für die Erntequalität aufgepreßt wurden, lieferten noch 1935 tabakmosaikvirushaltige Extrakte, die bei Pflanzen Läsionen verursachten.

Die früher einmal aufgestellte Regel, daß lipidfreie Viren besser bei hoher relativer Luftfeuchtigkeit und lipidhaltige eher bei niedriger Luftfeuchtigkeit persistieren, gilt nur sehr begrenzt für virushaltige Aerosole. Eine Fülle z. T. sehr widersprüchlicher Literaturangaben weist jedoch auch hier auf den hohen stabilisierenden Einfluß zusätzlicher Faktoren wie proteinhaltiger Sekrete hin.

Die Temperaturstabilität der Viren hängt anscheinend weniger vom Vorhandensein einer Hülle ab..Auch wenn Vi- 


\begin{tabular}{|c|c|c|}
\hline \multicolumn{3}{|c|}{ Hitzeinaktivierung von viren } \\
\hline $85.60 \mathrm{C} / 1 \mathrm{~h}$ & $65-700 \mathrm{C} / \mathrm{in}$ & $>900 \mathrm{C} / \mathrm{in}$ \\
\hline $\begin{array}{l}\text { Picomaviren } \\
\text { Herpesviren } \\
\text { Togaviren } \\
\text { Caliclviren }\end{array}$ & $\begin{array}{l}\text { Pockenuiren } \\
\text { Paramyxoviren } \\
\text { Reoviren } \\
\text { Adenoviren } \\
\text { Orthomyxoviren } \\
\text { Bunyaviren } \\
\text { Rhabdoviren } \\
\text { Arenaviren } \\
\text { Coronaviren } \\
\text { Retroviren }\end{array}$ & $\begin{array}{l}\text { Parvoviren } \\
\text { Hepadnaviren } \\
\text { Papovaviren }\end{array}$ \\
\hline
\end{tabular}

Tab. 2: Zuverlässige Inaktivierung virushaltigen Materials nach 1stündiger Wärmebehandlung (nach Mahnel, 1987).

ren insgesamt als temperaturlabil gelten, muß damit gerechnet werden, daß vor allem in Anwesenheit von Begleitsubstanzen (Blut, Eiweiß etc.) bei bestimmten Gruppen Temperaturen bis $90^{\circ} \mathrm{C}$ kurzzeitig toleriert werden können (vgl. Tab. 2).

Die Stabilität gegenüber Licht oder UV-Strahlung wird demgegenüber wohl eher durch den Bau der genetischen Informationen des Partikels bestimmt. Bei direkter Strahlenexposition werden Viren meist schnell inaktiviert; solche mit einsträngiger Nukleinsäure offenbar rascher.

Auf die Stabilität von Virus-Virus-Aggregaten wurde oben bereits hingewiesen; ebenso auf die Erhöhung der Resistenz von Virus-Proteinaggregaten. Eigene Experimente, aber auch ältere Arbeiten, haben einen hohen stabilisierenden Effekt durch Virusadsorption an Oberflächen gezeigt. Hierbei kann es sich sowohl um inanimate Flächen, z. B. aus Glas, Edelstahl, Kunststoff, Holz u. ä., als auch um Zelloberflächen handeln.

\section{Bakteriophagen und ihre Umwelt- und Chemikalienresistenz}

Mit Ausnahme weniger Arten wurde die Umwelt- und Chemikalienresistenz der Bakteriophagen bisher noch nicht systematisch untersucht. Aufgrund der vorhandenen Daten und der Biologie dieser Viren ist jedoch eine hohe Stabilität zu erwarten.

Bakteriophagen finden sich in der natürlichen Umwelt in zahlreichen Biotopen. Bestimmte Arten wurden daher bereits als "Leitviren” zur Beurteilung der Trinkwasserqualität vorgeschlagen, andere wieder als Prüfviren für Desinfektionsmitteltests.

Nach einem lytischen Replikationszyklus werden Phagen unter natürlichen Bedingungen direkt in die Umwelt ausgeschleust. Im Verglëich zu den Viren höherer Wirbeltiere oder des Menschen kommen als Stabilisatoren daher niemals Substanzen wie Blut, Rachensekret, Speichel etc. in
Frage, wohl aber Fäkalien, Urin, Schlamm, Tonmineralien u. ä., im Falle von Laktokokken-Phagen auch Milch.

In ihrer Morphologie zeigen Phagen große Unterschiede, die mit einer ebenso großen Heterogenität im Verhalten gegen chemische Desinfektionsmittel zu korrelieren scheint. In gewissen Grenzen verhalten sie sich ähnlich resistent wie z. B. Picornaviren (Poliovirus). Es gibt allerdings auch beträchtliche Abweichungen, so daß Bakteriophagen nur in Ausnahntefällen als Prüfviren für Desinfektionsmitteltests, z. B. für die Überprüfung von Haut- und Schleimhautdesinfektionsmittel Verwendung finden sollten, wo sie aus Sicherheitsgründen geeigneter scheinen.

\section{Unkonventionelle Viren und ihre Resistenzeigenschaften}

Man kennt heute einige Infekționskrankheiten des zentralen Nervensystems bei Menschen wie auch bei Haustieren, die durch eine vieljährige Inkubationszeit charakterisiert sind und nach ihrem Ausbruch über ein monatelanges kontinuierliches Fortschreiten zum Tod des Individuums führen. Sie werden durch die bereits genannten Prionen/Virinos verursacht.

Die jüngst bei Rindern aufgetretene spongiforme Encephalopathie BSE zählt ebenso zu diesem Krankheitstyp wie die Creutzfeldt-Jakob-Erkrankung des Menschen (Tab. 3). Darüber hinaus existieren noch eine Reihe anderer menschlicher Erkrankungen wie z. B. die multiple Sklerose, die Alzheimer Erkrankung, die Parkinsonsche Erkrankung und verschiedene weitere psychische Erkrankungen, für die ein ähnliches infektiöses Prinzip bislang nicht sicher ausgeschlossen werden kann.

Im Falle der Creutzfeldt-Jakob-Erkrankung finden sich die Erreger im Hirnmaterial und in geringen Konzentrationen

\begin{tabular}{|c|c|c|}
\hline Yusgippo & 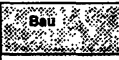 & 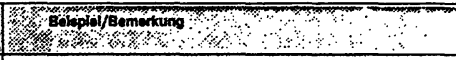 \\
\hline Adenoviren & unbehcillt/ONS & $\begin{array}{l}\text { humane Adenowiren, Ursacten z. B. for resplratorische } \\
\text { Enkrankungen, Keratokonjunkivivitis, Entrertiden }\end{array}$ \\
\hline Arenaviren & behalt/RNS & 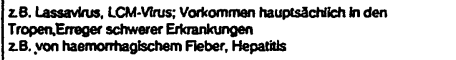 \\
\hline Bunyaviren & beholl/RNS & $\begin{array}{l}\text { Vorkommen in den Tropen, werden durch blunsaugende insekten } \\
\text { Obertragen, Ursache fiebriger Erkrankungen }\end{array}$ \\
\hline Calichiren & unbeholl/:RNS & Norwalk-Virus, Ursache einer Entertus bei Kndern \\
\hline Coronaviren & behOm/RNŚ & $\begin{array}{l}\text { humane Coronaviren, Ursache für Entertidien, respiratorische } \\
\text { Infekte. Pneumonlen }\end{array}$ \\
\hline Filoviren & beholn/RNS : & $\begin{array}{l}\text { 28. Marburg-Virus/Ebolavinus, Vorkornmen in den Tropen, Eneger } \\
\text { schwerer Erkrankungen, ZB. haemornthagischer Fieber }\end{array}$ \\
\hline Hepadnaviren & behoin/ONS & Hepathis Q-Vins, Emeger der klassischen Serum-Hepatitis \\
\hline Herpesviren & behult/DNS & 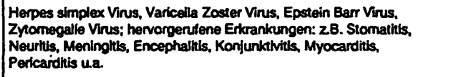 \\
\hline Orthomyxoviren & behOII/RNS & Influenzavirus A, B. und C., respiratorische Infekte, Grippe \\
\hline Papovaviren & unbeholit/DNS & $\begin{array}{l}\text { humane Papplonwiren, Warzen, Betelligung an der Genese be- } \\
\text { stimmter Tumorerkrankungen }\end{array}$ \\
\hline Paramyxoviren & behall/RNS & 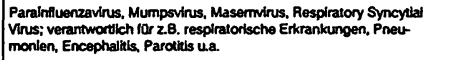 \\
\hline Parvoviren & unbehall/ONS & Panovinus B 19, Emeger der Ringedroteln \\
\hline Plcornaviren & unbehula/R/RS & 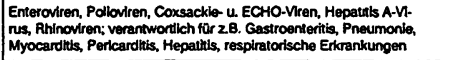 \\
\hline Pockemvien & behout/DNS & $\begin{array}{l}\text { humanes Pockeminus, git als ausgeroftet; Infektionen durch andere } \\
\text { SAlugetlerpocken werden auch heute noch beim Menschen beschrieben }\end{array}$ \\
\hline Reoviren & unbehollt/RNS & Rotavirus, Emterits bel Sauglingen \\
\hline Retroviren & behoth/FNS & Human Immunodeflency Vins, verantworvilch far AIDS \\
\hline Rhabdowiren & behOiln/RNS & Rablesvirus, verantwortich fïr Toltwist \\
\hline Togáviren & beholit/RNS & $\begin{array}{l}\text { Gelbrlebervirus, } \\
\text { Roldimwirus: verantwortlch for Fleber, Hauterscheinungen, Terato- } \\
\text { gones Virus }\end{array}$ \\
\hline $\begin{array}{l}\text { unkonvem. } \\
\text { Viren }\end{array}$ & Prionen & $\begin{array}{l}\text { Crevitzdeldt Jakob-Enkrankung, chronksch } \\
\text { degenerative Hilmerkankung }\end{array}$ \\
\hline
\end{tabular}

Tab. 3: Übersicht der wichtigsten humanipathogenen Viren. 
DasLS5001stdascregj strterende UVWMISS petso cralphotometervon Dr. Langefüranspruchs volle Untersuchungen ton der Laboratoritumsmedizin. Mits neuer Aus: wertungssofftware, großer Mechodenviels. failsundleitchter Bedienungutum Dialos. Whe ub berzeugend das Konzeppedes LS500 ist, zeiggsich andeuts Nichstenninseiner Ents whickl longostonur einem J ahos hat sichodas LS500 eline Vielzatio von Einsatzgebieten eroberb denn die melsten Laboreund Q Kliniken finden um LS500 exihresAdapo tionen. Oncurrefinem fahr has sich diezahldervers. fügbaren:Adaptionen von 80 auffin 0erhônte. Undthnurefinemijahs thabensich die:Insteallas tîonenvervielfiachcs Eine Entwickling, anderSietefilhabern sollten.

Dr:BrunoLangeGmbH Kỏnfigsweg 10 D-1000Berfin 37 Teléfon (030) 81602 $=0$

\section{ist so spektakullär. . .}

\section{... daß Sie dringend daran teilhaben \\ sollten.

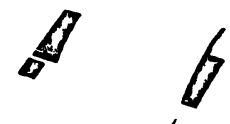

Fordern Sie mit dieser

Antwortkarte weitere Informationen oder eine Probestellung an. Außerdem kommen Sie damit automatisch in den Verteiler für alle geplanten wissenschaftlichen Aufsätze über das LS 500 .

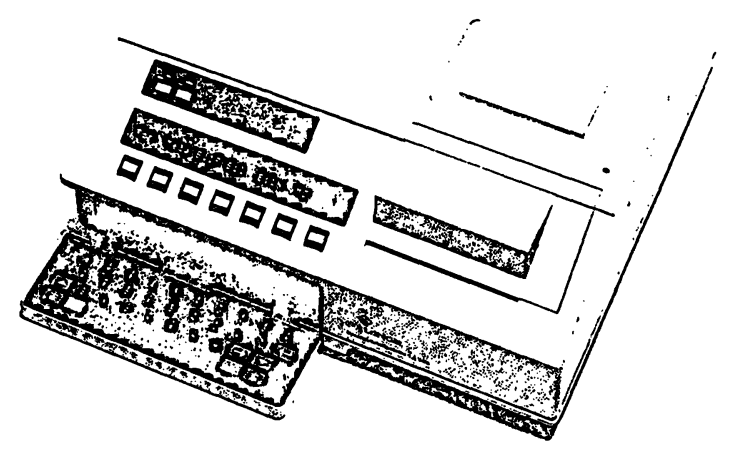




\section{Dio auslegevolichtigen Priasoisvorsobititen}

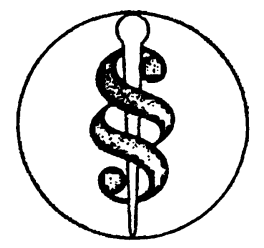

GESAMTISEUTSCHE AUSCABE

\section{(Ärzte, Zahnärzte, Tierärzte) von W. M. Nentwig (Notar) und R. J. Gläser (Rechtsanwalt)}

216 Seiten, Broschur, 39,80 DM, ISBN 3-87409-182-1, 3. überarbeitete Auflage

Eine komplette Sammlung aller Gesetze und Verordnungen, die in jeder Praxis ausgelegt werden müssen. Geldbußen bis zu 1.000 DM drohen, wenn auslegepflichtige Vorschriften dem (ohne vorherige Anmeldung in der Praxis erscheinenden) Beamten des Gewerbeaufsichtsamtes nicht vorgelegt werden können.

Jugendarbeitsschutzgesetz, wenn regelmäßig mindestens ein Jugendlicher beschäftigt wird,

- Nutterschutzgesetz, wenn regelmäßig mehr als drei Frauen beschäftigt werden,

o die Arbeitszeitordnung in jedem Fall,

- die Unfallverhütungsvorschrift (Berufsgenossenschaft) in jedem Fall

O die Röntgenverordnung, wenn ein Röntgengerät betrieben wird,

$\boldsymbol{O}$ das Bestandsverzeichnis oder Gerätebuch gem. Medizingeräteverordnung, wenn energetisch betriebene med.technische Geräte betrieben werden.

Kann ein Bestandsverzeichnis oder Gerätebuch nicht vorgelegt werden, droht eine Geldbuße bis zu 10.000 DM!
Die Anschaffung dieses Werkes kann daher ohne Übertreibung als "Pflichtlektüre für jede Praxis" bezeichnet werden. Demgemäß sind die Anschaffungskosten selbstverständlich als Praxisausgaben steuerlich absetzbar.

Jetzt als "gesamtdeutsche" Ausgabe mit den Ergänzungen des Einigungsvertrages und dessen Auswirkungen auf Praxen und ärztlich geleitete Polikliniken in den fünf neuen Bundesländern. Darüber hinaus wurden die verlängerten Fristen zur Abnahme von Röntgengeräten gemäß $\$ 45$ Abs. 3 RöV sowie die neue Verordnung über die ärztlichen Untersuchungen nach dem Jugendarbeitsschutzgesetz eingearbeitet.

\section{$C$}

Postfach 25 24, 6500 Mainz, Telefon 061 31/67 1081

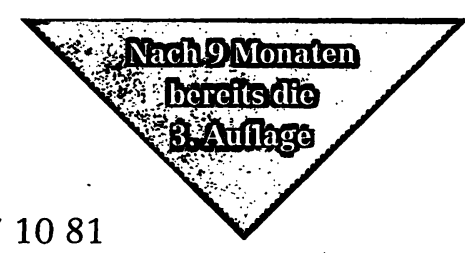

Ich bestelle ... Exemplare:

Nentwig/Gläser

Die auslegepflichtigen

Praxisvorschriften

ISBN 3-87409-182-1,
Name:

Straße:

PLZ/Ort:

Datum/Unterschrift: 
auch im Blut und in den Organen und zeichnen sich durch eine geradezu verblüffende Resistenz aus. Man konnte z. B. zeigen, daß formalinfixiertes, paraffineingebettetes Hirnmaterial eines Creutzfeldt-Jakob-Erkrankten noch nach zwei Jahren eine Restinfektiösität hat und dies nach dem Schmelzen des Paraffins, einer Entparaffinierung in Xylol und der Rekonstituierung der Probe in einer absteigenden Alkoholreihe. Selbst Autoklavieren über eine Dauer von $\mathbf{3 0}$ Minuten wird als nicht ausreichend für die Inaktivierung dieser Partikel angesehen. Tabelle 4 listet einige Resistenzeigenschaften von Prionen auf.

\section{Wichtige Viren und ihre Übertragungswege}

Eine Auflistung der wichtigsten humanpathogenen Viren findet sich in Tabelle 3; die bedeutendsten nutztierpathogenen Viren werden in Übersicht 5 zusammengefaßt. Einige von ihnen sind in der Lage, auch den Menschen zu infizieren. Hierfür wurde der Begriff "Zoonose” geprägt.

Die Infektionswege der wichtigsten humanpathogenen Viren sind in Übersicht 6 aufgeführt. Eine Zusammenstellung der wichtigsten Patientenmaterialien, die als Infektionsquelle in Betracht kommen können, findet sich dagegen in Tabelle 7. Letztere kann jedoch nur einen ungefähren Anhalt für die Zeit der akuten Erkrankung geben. Insbesondere vor und nach der Phase akuter Krankheitssymptomatik kommen auch andere Patientenmaterialien als Infektionsquellen in Frage.

Ein anderes Problem bildet die hohe Durchseuchung der Erwachsenenbevölkerung mit latenten persistierenden Viren, z. B. mit Herpes simplex Virus Typ 1 (HSV 1), aber auch diejenige mit Typ 2 (HSV 2). Hier kann die Bekämpfung durch Desinfektionsmittel aus epidemiologischen Gründen nur auf wenige und sehr spezielle Bereiche,

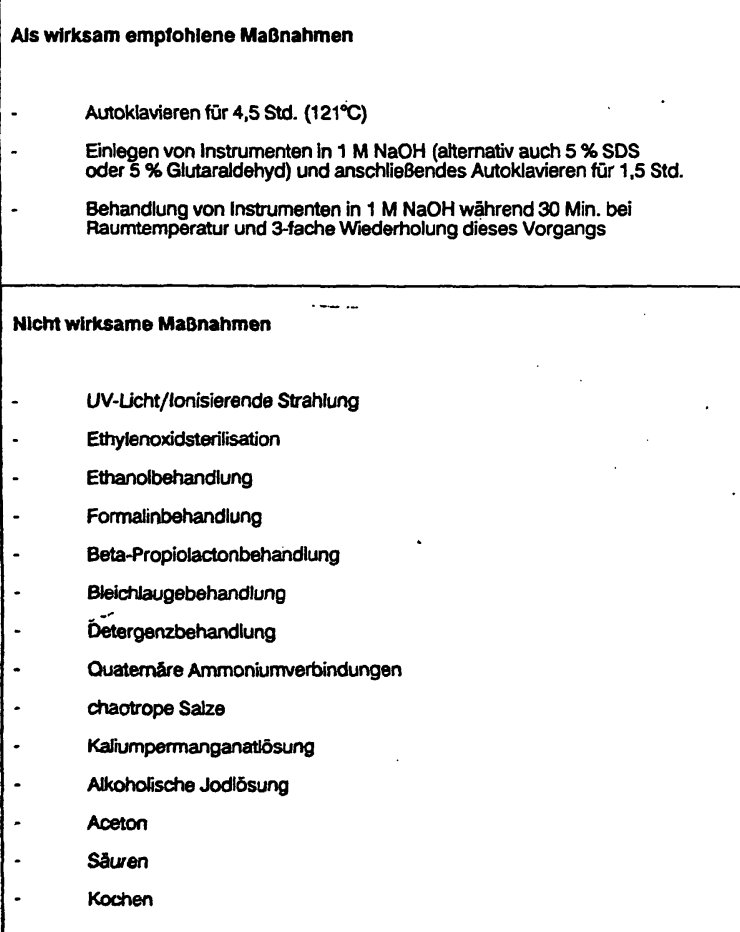

Tab. 4: Wirksame und unwirksame Maßnahmen beim Umgang mit prionenhaltigem Material.
2. B. in der Ophthalmologie (HSV 1: Tonometer, Kontaktlinsen) oder der Gynäkologie (HSV 2: Gynäkologisches Instrumentarium) beschränkt bleiben. Auch in Säuglingsstationen kann versucht werden, durch entsprechende Hygienemaßnahmen, etwa durch eine Händehygiene, die frühzeitige Durchseuchung von Neugeborenen zu verhindern. In anderen Bereichen scheint dagegen der Einsatz von Desinfektionsmitteln zur Bekämpfung derartiger Viren wenig sinnvoll.

Bei der Durchführung von Desinfektionsmaßnahmen ist ferner zu bedenken, daß die Weitergabe nicht ausschließlich den genannten Wegen folgen muß: Ebenso wie es im Tierversuch möglich ist, nahezu jedes typischerweise fäkal-oral weitergegebene Virus durch Aerosole zu übertragen, können auch typischerweise aerogen übertragene Viren durch direkte und indirekte Kontakte weitergegeben werden.

Wegen ihrer großen Bedeutung wurden die Hepatitisviren in einer gesonderten Übersicht zusammengestellt (Tab. 8). Das dort aufgeführte Hepatitis $C$ und das E-Virus (HCV, HEV) wurde erst kürzlich charakterisiert. Früher sind beide Viren unter den Namen Non-A, Non-B zusammengefaßt worden.

\begin{tabular}{|c|c|c|}
\hline Viruspopo & Empixngichepran & Wonngin Wirusan/Krankheit \\
\hline Adenoviren & $\begin{array}{l}\text { Hund } \\
\text { Săugetiere } \\
\text { Geflugel }\end{array}$ & $\begin{array}{l}\text { Hundehepatitis } \\
\text { 2.B. Enteritiden } \\
\text { Küken-Leberzellnekrose }\end{array}$ \\
\hline Arenaviren & Nagetiere & Lymphozytãre Choriomeningitis \\
\hline Birnaviren & Huhn & Infektiōse Bursitis \\
\hline Caliciviren & $\begin{array}{l}\text { Schwein } \\
\text { Katze }\end{array}$ & $\begin{array}{l}\text { Vesikulärexanthem } \\
\text { Schnupfen }\end{array}$ \\
\hline Coronaviren & $\begin{array}{l}\text { Sâugetiere } \\
\text { Schwein } \\
\text { Huhn } \\
\text { Katze }\end{array}$ & \begin{tabular}{|l|} 
Enteritiden \\
übertragbare Gastroenteritis \\
Infektióse Bronchitis \\
Infektiose Peritonitis
\end{tabular} \\
\hline Herpesviren & $\begin{array}{l}\text { Säugetiere } \\
\text { Rind } \\
\text { Plerd } \\
\text { Pferd } \\
\text { Huhn } \\
\text { Huhn } \\
\text { Katze }\end{array}$ & $\begin{array}{l}\text { Aujeszky'sche Krankheit } \\
\text { IBR-IPV } \\
\text { Rhinopneumonitis-Stutenabort } \\
\text { Exanthema coitale } \\
\text { Iffektóse Larygotracheitis } \\
\text { Mareksche Hutunnerlähmung } \\
\text { Rhinotracheitis }\end{array}$ \\
\hline Iridoviren & Schwein & Afrikanische Schweinepest \\
\hline Orthomyxoviren & Sāuger, Geflūgel & Influenza \\
\hline Papovaviren & Sãuger & Papillomviren \\
\hline Paramyxoviren & $\begin{array}{l}\text { Saluger } \\
\text { Geffugel } \\
\text { Hund } \\
\text { Find } \\
\text { Schat/Ziege }\end{array}$ & $\begin{array}{l}\text { Parainfluenza, Respiratory-Syncytial Viren } \\
\text { Newcastle Disease } \\
\text { Staupe } \\
\text { Rinderpest } \\
\text { Pest kleiner Wiederkăuer (PPR-Virus) }\end{array}$ \\
\hline Panoviren & $\begin{array}{l}\text { Rind/Schwein } \\
\text { Hund } \\
\text { Katze } \\
\text { Nerz } \\
\text { Gans }\end{array}$ & $\begin{array}{l}\text { Parvovirosen } \\
\text { Gastroenteritis, Myocarditis } \\
\text { Panleukopenie } \\
\text { Nerzenteritis } \\
\text { Gánsehepatitis }\end{array}$ \\
\hline Picomaviren & $\begin{array}{l}\text { Wiederkåuer/Schwein } \\
\text { Sauger } \\
\text { Schwein } \\
\text { Pferd/Rind } \\
\text { Huhn } \\
\text { Ente }\end{array}$ & $\begin{array}{l}\text { Maul- und Kauenseuche } \\
\text { Enteroviren / Teschener Krankheit } \\
\text { Vesikuläre Schweinekrankheit } \\
\text { Rhinoviren / Schnupfen } \\
\text { Kükenencephalomyelitis } \\
\text { Entenhepattis }\end{array}$ \\
\hline Pockenviren & $\begin{array}{l}\text { Sāuger/Geflügel } \\
\text { Kaninchen } \\
\text { Rind / Schaf }\end{array}$ & $\begin{array}{l}\text { Pocken } \\
\text { Myxomatose } \\
\text { Parapocken / Ecthyma }\end{array}$ \\
\hline Reoviren & $\begin{array}{l}\text { Săuger / Genügel } \\
\text { Sauger } \\
\text { Pferd } \\
\text { Schat } \\
\end{array}$ & $\begin{array}{l}\text { Reoviren } \\
\text { Rotavinus-Enteritiden } \\
\text { Afrikanische Plerdepest } \\
\text { Bluetongue } \\
\end{array}$ \\
\hline Retroviren & $\begin{array}{l}\text { Saugger, Geflügel } \\
\text { Plerd } \\
\text { Schat/Ziege }\end{array}$ & $\begin{array}{l}\text { Leukămien, Sarkome } \\
\text { Infektiôse Âămie } \\
\text { Visna-Ṃaẹ̣i }\end{array}$ \\
\hline Rhabdoviren & $\begin{array}{l}\text { Săuger } \\
\text { Plerd/Rind }\end{array}$ & $\begin{array}{l}\text { Tollmut } \\
\text { Stomatutis vesicularis }\end{array}$ \\
\hline Togaviren & $\begin{array}{l}\text { Studer } \\
\text { Rind } \\
\text { Wiederkáuer } \\
\text { Plerd }\end{array}$ & $\begin{array}{l}\text { Europălsche Schweinepest } \\
\text { Mucosal Disease/Nirusdiarhoe } \\
\text { Zeckenencephalitis } \\
\text { Encephalomyelitiden }\end{array}$ \\
\hline $\begin{array}{l}\text { unklassiff- } \\
\text { zierte } \\
\text { Viren }\end{array}$ & Pferd, Schat & Bornasche Krankheit \\
\hline $\begin{array}{l}\text { Unkonven- } \\
\text { tionelle } \\
\text { Viren }\end{array}$ & Schaf / Aind & Scrapie / BSE \\
\hline
\end{tabular}

Tab. 5: Übersicht der wichtigsten haustierpathogenen Viren. 


\begin{tabular}{|c|c|}
\hline Obertragen duren: & Bctiplate \\
\hline Kontakt & $\begin{array}{l}\text { Adenoviren } \\
\text { Parvoviren } \\
\text { Herpesviren } \\
\text { Orthomyo-, Paramyxoviren } \\
\text { Papovaviren } \\
\text { Pockemviren }\end{array}$ \\
\hline Sexualverkeh & $\begin{array}{l}\text { Herpes simplex Virus Typ } 2 \\
\text { Hiv. } 1 \text { und -2 } \\
\text { Hepatits B-Virus } \\
\text { Hepetitis C-Virus } \\
\text { Papillomviren }\end{array}$ \\
\hline $\begin{array}{l}\text { Fákal-orale Infoktlon/ } \\
\text { Schmierinfoktion }\end{array}$ & $\begin{array}{l}\text { Adenoviren (v. a. die Typen 8, 40,41) } \\
\text { Coxsackie-, ECHO-, Polio-, Hepatitis A. } \\
\text { und andere Enteroviren } \\
\text { Calichiren: Norwalkvirus, Hepatitis E-Virus } \\
\text { Rotaviren } \\
\text { Coronaviren } \\
\text { Rotelmirus }\end{array}$ \\
\hline $\begin{array}{l}\text { Aerogen durch Aerosole } \\
\text { und } \% \text { oder durch Staub }\end{array}$ & $\begin{array}{l}\text { Adenoviren (v.a die Typen 4, } 7 \text { ) } \\
\text { Varizella Zoster Virus } \\
\text { zaromegalievius } \\
\text { Aotelnuirus } \\
\text { influenzavirus A, B und C } \\
\text { Mumps-, Masern-, RSV } \\
\text { Coronaviren } \\
\text { Parvoviren } \\
\text { Rhinoviren } \\
\text { Polioviren } \\
\text { Pockenviren }\end{array}$ \\
\hline Vektoren & $\begin{array}{l}\text { Bunyaviren } \\
\text { Flaviviren, insbesondere FSME-Virus }\end{array}$ \\
\hline BiB eines erkrankten Tieres & Rabiesvirus \\
\hline $\begin{array}{l}\text { Parenteral / Blut, } \\
\text { Blutprodukte }\end{array}$ & $\begin{array}{l}\text { Hepatitis B-Virus / D-Virus } \\
\text { Hepatitis C-Virus } \\
\text { HN-1 und -2 } \\
\text { Zytomegalie-, Epstein-Barr-Virus } \\
\text { Parvovirus B19 }\end{array}$ \\
\hline latrogen & $\begin{array}{l}\text { Hepatitis B-Virus / D-Virus } \\
\text { Hepatitis C-Virus } \\
\text { HIV-1 und -2 } \\
\text { Herpesviren } \\
\text { Adenoviren }\end{array}$ \\
\hline Transplantate & $\begin{array}{l}\text { Hepatitis B-Virus, D-Virus } \\
\text { Herpes simplex Virus } \\
\text { Varizella Zoster Virus } \\
\text { Zytomegalievirus } \\
\text { Creutzfeld-Jakob Erkrankung }\end{array}$ \\
\hline
\end{tabular}

Tab. 6: Hauptübertragungswege der wichtigsten humanpathogenen Viren.

Was ihre Resistenz gegenüber chemischen Inaktivierungsmitteln anbelangt, so bietet sich bei HCV der Vergleich mit HBV und bei HEV der Vergleich mit Hepatitis-AVirus an.

\section{Chemische Desinfektionsmittel}

Durch Desinfektionsmittel können alle bisher angesprochenen konventionellen Viren wirksam bekämpft werden. Neben universellen Flächen-, Instrumenten-, Hände-I

\begin{tabular}{|c|c|}
\hline Pattentenmiterial & Mogiliche Viruskontamination durch: \\
\hline $\begin{array}{l}\text { Biopsiematerial, } \\
\text { Sektionsmaterial }\end{array}$ & $\begin{array}{l}\text { Hepatitis B-, C, D-Virus, } \\
\text { Hiv-1 und - } 2 \text {, darCberhinaus aber auch alle } \\
\text { Obrigen Virusgruppen, einschließlich } \\
\text { unkorventioneller Viren. }\end{array}$ \\
\hline Blut/Sorum & $\begin{array}{l}\text { Hepatitis B-, C., D-Virus } \\
\text { HN-1 und -2 } \\
\text { Zyromegalie-Epstein Barr Virus } \\
\text { Parvovinus Bi9 }\end{array}$ \\
\hline Uquor & $\begin{array}{l}\text { Mumps-, Masernvirus } \\
\text { Herpes simplex Virus Typ } 1 \\
\text { Polio-, ECHO-Viren } \\
\text { Rabiesvins } \\
\text { Unkonventionelle Viren }\end{array}$ \\
\hline $\begin{array}{l}\text { Speichel, Nasern- und } \\
\text { Rachensekret }\end{array}$ & $\begin{array}{l}\text { Adenowirus } \\
\text { Rhinoviren } \\
\text { Coxsackie A-Viren } \\
\text { Rơtelnvirus } \\
\text { influenzaviren A, 8, C. } \\
\text { Parainfluenzaviren, v. a. Masern-, Mumps-, RSV }\end{array}$ \\
\hline Sputum & $\begin{array}{l}\text { Adenoviren } \\
\text { Influenza-, Parainfluenza-, RSV }\end{array}$ \\
\hline $\begin{array}{l}\text { Konjunktivales } \\
\text { Abstrichsmaterial }\end{array}$ & $\begin{array}{l}\text { Herpes simplex Virus } \\
\text { Adenovirus }\end{array}$ \\
\hline $\begin{array}{l}\text { Vaginales Abstrichs- } \\
\text { material }\end{array}$ & $\begin{array}{l}\text { Herpes simplex-, Zytomegalievirus } \\
\text { Papillomviren } \\
\text { Hiv-1 und -2 } \\
\text { Hepatitis B-Virus }\end{array}$ \\
\hline Urin & $\begin{array}{l}\text { Zytomegalievirus } \\
\text { Mumpsvirus } \\
\text { Arenaviren } \\
\text { Hepatitis B-Virus }\end{array}$ \\
\hline Stuhl & $\begin{array}{l}\text { Adenoviren } \\
\text { Rotaviren } \\
\text { Coronaviren } \\
\text { Caliciviren } \\
\text { Entero-, Coxsackie-, ECHO-, Polio- und } \\
\text { Hepatitis A-Virus } \\
\text { Hepatitis E-Virus }\end{array}$ \\
\hline Muttermilch & HIV-1 und -2 \\
\hline
\end{tabular}

Tab. 7: Patientenmaterialien als Infektionsquelle; die Tabelle zeigt, mit welchen Kontaminationen in welchem Material gerechnet werden muß.

Haut- und Spray-Desinfektionsmitteln gibt es eine Reihe von Spezialprodukten, die dem Einsatz in speziellen Bereichen, z. B. der maschinellen Desinfektion, der Desinfektion von Dialyseapparaturen, Endoskopen, Tonometern usw. vorbehalten bleiben und auf deren Viruswirksamkeit ebenso Wert zu legen ist.

Moderne Desinfektionspräparate müssen heute neben einem breiten Wirkungsspektrum gegen Krankheitserreger auch einer Vielzahl anderer Kriterien genügen: Sie müssen vor allem toxikologisch unbedenklich sein, sollen also kein allergenes, mutagenes oder kanzerogenes Potential besitzen. Sie müssen darüber hinaus auch ökolo-

\begin{tabular}{|c|c|c|c|c|}
\hline Wrus? & 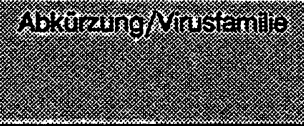 & 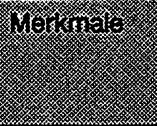 & 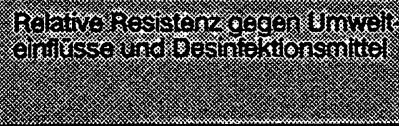 & 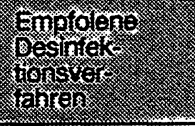 \\
\hline Hepatitis A & $\begin{array}{l}\text { HAV/ Picornaviridae } \\
\text {. }\end{array}$ & $\begin{array}{l}\text { RNS/ unbe- } \\
\text { hült, } \\
\text { hydrophil }\end{array}$ & sehrhoch & $\begin{array}{l}\text { wie z.B. für } \star \star \\
\text { Poliovirus nach } \\
\text { DWV-Richtlinie }\end{array}$ \\
\hline Hepatitis B & HBV/ Hepadnaviridae & $\begin{array}{l}\text { DNS/ } \\
\text { behullt }\end{array}$ & hoch & HBV * \\
\hline Hepatitis C & HCV/ Flaviviridae & $\begin{array}{l}\text { RNS/ } \\
\text { lipophil }\end{array}$ & $\begin{array}{l}\text { bei Flaviviren } \\
\text { eher gering }\end{array}$ & HBV * \\
\hline Hepatitis D & \multicolumn{2}{|c|}{$\begin{array}{l}\text { HDV/ "Viroid"-āhnliche RNA } \\
\text { mit Hüllbestandteilen des HBV }\end{array}$} & ãhnlich Hepatitis B & HBV * \\
\hline Hepatitis E & HEV/ Caliciviridae & $\begin{array}{l}\text { RNS/ } \\
\text { unbehült }\end{array}$ & sehr hoch & $\begin{array}{l}\text { wie z.B.fūr } * * \\
\text { Poliovirus nach } \\
\text { DW-Richtlinie }\end{array}$ \\
\hline
\end{tabular}

Tab. 8: Einteilung und Resistenz der klassischen" Hepatitisviren (*Einsatz von Hepatitis B-Virus-wirksamen Desinfektionsmitteln, deren Wirksamkeit z. B. im morphologischen Alterations- und Desintegrationstest festgestellt wurde, ${ }^{*}$ bzw. deren Wirksamkeitsaussage das Testergebnis gegenüber Poliovirus nach DVV-Prüfung zugrunde liegt). 
gisch unbedenklich und biologisch wieder gut abbaubar sein. Ferner sollten sie sowohl eine gute Materialverträglichkeit als auch eine gute Hautverträglichkeit aufweisen.

Hände- und Hautdesinfektionsmittel unterliegen in Deutschland sogar den strengen Zulassungsbestimmungen, die auch für Arzneimittel gelten.

Bei den genannten Anforderungen handelt es sich um einen Katalog von Minimalforderungen, der je nach Verwendungszweck erheblich erweitert wird. So ist leicht verständlich, daß heute dem Einsatzbereich entsprechende Spezialprodukte verwendet werden müssen. Durch diese Anforderungsprofile schränkt sich aber auch die Anzahl der Desinfektionsmittelwirkstoffe erheblich ein. Trotzdem bestehen moderne Präparate heute aus komplizierten Rezepturen, oft mit mehr als einem Dutzend Einzelkomponenten. Neben Wirkstoffen enthalten sie eine Reihe nicht wirksamer Bestandteile wie Netzmittel, Korrosionsinhibitoren, Stabilisatoren, Substanzen zur Verbesserung der Hautverträglichkeit und vieles andere mehr.

\section{Faktoren, die die viruzide Wirksamkeit eines Desinfektionsmittels beeinflussen}

Alle genannten Faktoren, die die Stabilität der Viren beeinflussen, wie zum Beispiel deren Bau, Aggregationsgrad, Reinheitsgrad, Zusätze von Eiweiß, Serum, Milch, Blut usw., Assoziation an Zell- und inanimate Oberflächen, Trockungsgrad oder Temperatur bestimmen auch das Verhalten bei einer chemischen Inaktivierung.

Die Wirksamkeit des Desinfektionsmittels wird dagegen durch eine Reihe zusätzlicher Parameter beeinflußt. Hier sind vor allem zu nennen:

- Die Zusammensetzung der Desinfektionsmittelrezeptur.

- Die Stabilität und Reaktivität der einzelnen wirksamen, aber auch der sogenannten „nichtwirksamen Bestandteile". Sie können einen erheblichen modifizierenden Einfluß haben.

\begin{tabular}{|c|c|c|}
\hline 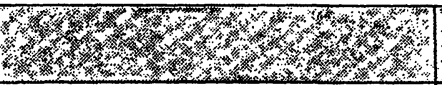 & 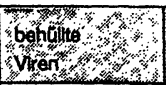 & 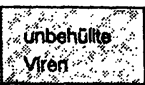 \\
\hline Basen & + & $+1-$ \\
\hline Săuren & + & $+1-$ \\
\hline Peressigsâure & + & + \\
\hline Formaldehyd & + & + \\
\hline Glyoxal & + & $+1-$ \\
\hline Glutaraldehyф & + & + \\
\hline Phenole und Derivate & $+1-$ & - \\
\hline Quaternäre Ammoniumverbindung & + & - \\
\hline Amphotenside & + & - \\
\hline Ethanol & + & $+1-$ \\
\hline n-Propanol & + & - \\
\hline Butanol & + & - \\
\hline iso-Propanol & + & - \\
\hline Jod U. Jodophore & + & $+1-$ \\
\hline Chlor und Chlorverbindungen & + & + \\
\hline Aktivsauerstoff-freisetzende Mittel & + & + \\
\hline
\end{tabular}

(+ - wirkacm, +1 - unsechor, - - unwirksam)

Tab. 9: Wirksamkeit der wichtigsten Basisbestandteile von Desinfektionsmittelrezepturen gegenüber behültten und unbehüllten Viren.

- Die Anwendungskonzentration des Mittels, das zumeist als Konzentrat geliefert und vom Anwender entsprechend der gewünschten Wirksamkeit verdünnt wird.

- Die Einwirkungszeit.

- Der pH-Wert.

- Sonstige organische und anorganische, gelöste oder suspendierte Bestandteile, wie sie etwa über das Wasser zum Ansetzen der Desinfektionsmittelverdünnung eingebraçht werden können.

- Die Temperatur, bei der die Desinfektion stattfindet, wobei deren Erhöhung fast ausnahmslos die Wirksamkeit potenziert.

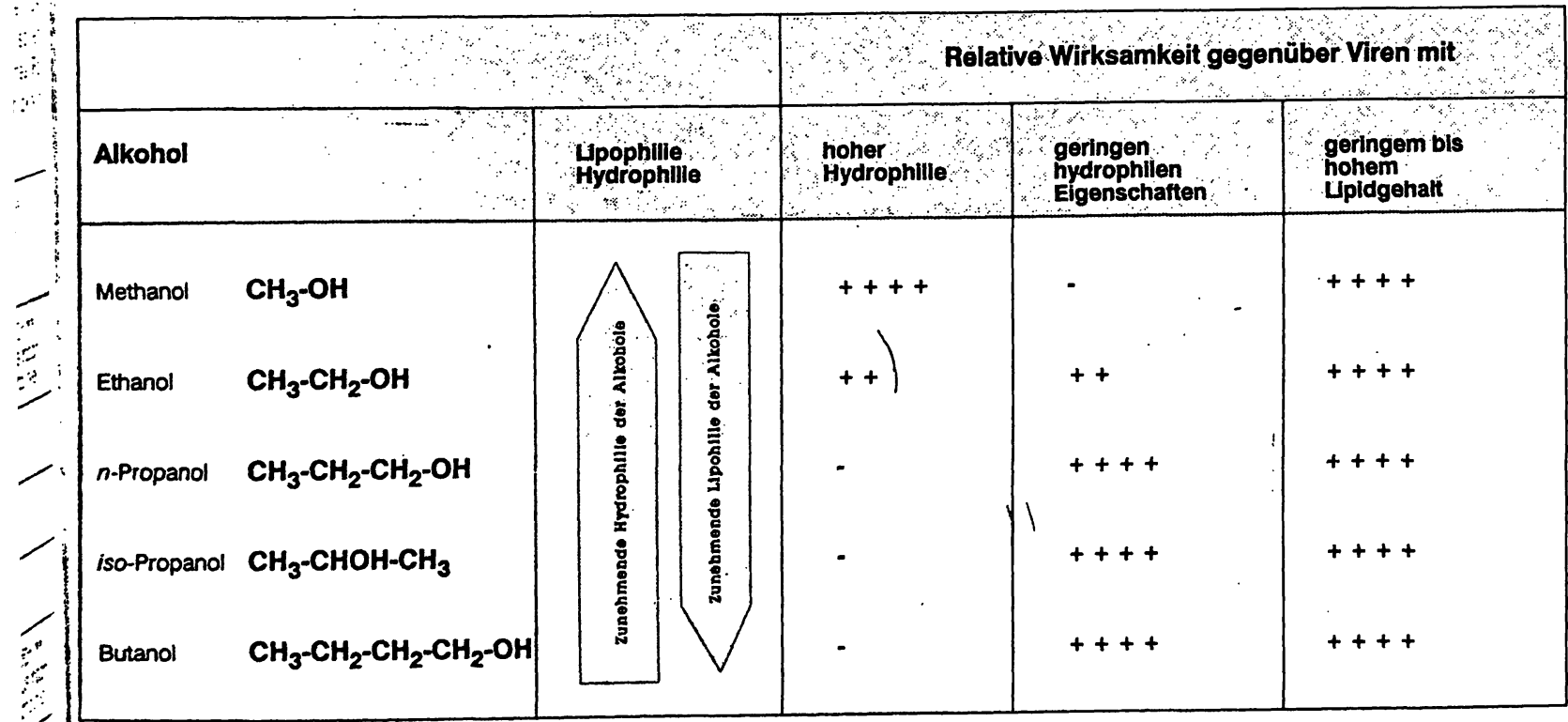

Tab. 10: Relative Wirksamkeit verschiedener Alkhole in Abhängigkeit vom Grad ihrer Lipophilie gegenüber den verschiedenen Virusgruppen (gute Wirksamkeit ++++ , geringe Wirksamkeit ++ , fehlende Wirksamkeit - ). 
Durch ihre Unterteilung in behüllte Viren mit eher lipophilen Eigenschaften und unbehüllte Viren mit meist hydrophilen Eigenschaften unterscheiden sich Viren im Hinblick auf ihre Empfindlichkeit gegenüber Desinfektionsmittelinhaltsstoffen. Tabelle 9 soll hier eine Hilfe zur groben Beurteilung der Viruzidie bzw. Teilviruzidie dieser Rezepturen sein, auch wenn nicht auf die beiden sehr wichtigen Einsatzparameter von Desinfektionsmittelkonzentration und Einwirkzeit eingegangen wird, die im Einzelfall zu völlig anderen Wirksamkeitsaussagen führen können.

Ebenso kann durch die Kombination unterschiedlicher Wirkstoffe die Wirksamkeit stark verändert werden, wobei auch hier die Wirkung eines Inhaltsstoffes verstärkt, möglicherweise aber auch vollständig aufgehoben wird. Letzteres gilt insbesondere für die Kombination mit oberflächenaktiven Substanzen oder Reinigungsmitteln.

Die Bekämpfung von Viruskrankheiten durch Desinfektion sollte stets von Hygienemaßnahmen flankiert werden, auf die hier jedoch nicht eingegangen werden kann.

\section{Mechanismus der Virusinaktivierung durch Desinfektionsmittel}

Der Wirkungsmechanismus chemischer Desinfektionsmittel auf Viren ist bisher noch weitgehend unbekannt. Im allgemeinen testet man nur die Wirksamkeit eines Basisrohstoffes, einer Rezeptur oder eines Handelsproduktes gegen bestimmte Prüfviren.

Für einzelne Wirkstoffe aber, z. B. für quaternäre Ammoniumverbindungen (QAV), Alkohole, Aldehyde, Halogenverbindungen oder Ozon wurden jedoch Untersuchungen durchgeführt, die eine Vorstellung vom Wirkungsmechanismus der chemischen Virusdesinfektion liefern.

Am Beispiel von Alkoholen soll hier ein solches Wirkungsprinzip beschrieben werden (Tab. 10):

Alkohole, aber auch oberflächenaktive Substanzen lösen die Hüllen lipophiler, behüllter Viren sehr rasch auf. Die Partikel können nicht mehr in ihre Wirtszellen eindringen (vgl. Abb. 2). Bei den unbehüllten, aber mit Lipiden reagierenden Viren dagegen, z. B. bei Adenoviren, haben nur längerkettige Alkohole eine Wirksamkeit. Diese zeigen mit zunehmender Kettenlänge ein wachsendes Fettlösungsvermögen und reagieren daher deutlich besser mit Adenoviren.

Die Denaturierung der Capsidproteine und Inaktivierung eines typischen hydrophilen Virus, z. B. Poliovirus, gelingt dagegen nur noch mit kurzkettigen Alkoholen. Eine Wirksamkeit gegen alle Gruppen von Viren ist daher mit Alkoholen allein kaum zu erreichen.

Während der Wirkung von Alkoholen Löslichkeitsphänomene zugrunde liegen, beruht die Wirkung von Aldehyden eher auf chemischen Bindungen. Hierbei scheint vor allem die Nukleinsäure im Partikelinneren betroffen zu sein. Aldehyde reagieren aber z. B. auch mit den Aminogruppen des Proteincapsids, also auch mit viralen Oberflächenbestandteilen. Die damit verbundene "Härtung" des Viruspartikels wurde daher für die vergleichsweise langsame Virusinaktivierung durch Aldehyde verantwortlich gemacht.

Daß mit zunehmender Kettenlänge, also einer ebenfalls zunehmenden Lipophilie der Aldehyde, auch ein Löslichkeitsphänomen ähnlich der Alkoholwirkung beobachtet wird, sei zum Schluß ebenso erwähnt, wie die Beschleunigung der chemischen Reaktion durch Verschiebung des $\mathrm{pH}$-Wertes in den alkalischen Bereich.

\section{Richtlinien als Basis für eine Wirksamkeitsaussage}

In grober Näherung wurden behüllte Viren in ihren Resistenzeigenschaften gegenüber Desinfektionsmitteln schon mit vegetativen Bakterien verglichen. Unbehülite Viren zeigen jedoch eine Resistenz, die durchaus mit derjenigen von Sporen verglichen werden kann. Um hier zu einer verläßlicheren Aussage zu gelangen, wurden Viruzidietests entwickelt; von einem Präparat müssen bestimmte Prüfkriterien erfüllt werden.

In Deutschland werden gemäß den Richtlinien der "Deutschen Vereinigung zur Bekämpfung der Viruserkrankungen (DVV)" aus jeder der drei obengenannten Viruskategorien Vertreter ausgewählt: Polio-, Adeno-, Vakziniaund Simianvirus 40. Die Desinfektionsmittel werden in einem Suspensionstest bei definierten Anwendungsbedingungen (Einwirkzeit, Anwendungskonzentration, Temperatur) geprüft und müssen die Anzahl der Prüfviren um mindestens 4 Zehnerpotenzen senken. Durch Serumbzw. Eiweißzugabe wird zusätzlich der Einfluß organischer Belastungen geprüft.

Für den veterinärmedizinischen Bereich gelten die Richtlinien der "Deutschen veterinärmedizinischen Gesellschaft DVG". Hier werden Wirksamkeitsprüfungen an Reo- und Rinderenteroviren (ECBO) sowie an Newcastle Diseaseund Vakziniavirus verlangt. Neben einem Suspensionstest muß auch die Inaktivierung der Viren an Holz- und Stoffträgern sichergestellt werden. Wird nur eine selektive Wirksamkeit gegen die beiden behüllten Prüfviren (Vakzinia- und NDV) festgestellt, so ist auch die Deklaration einer Teilviruzidie zulässig. Bei einer Wirksamkeit gegen alle vier Prüfviren ist das Mittel als uneingeschränkt viruzid anzusehen.

Ein besonderes Problem bereitet das Hepatitis-B-Virus, welches sich nicht in Zellkulturen vermehren läßt und dessen Aktivität nach Einwirkung chemischer Desinfektionsmittel daher nicht ohne weiteres überprüfbar ist. Hier müssen indirekte Tests, wie z. B. der Morphologische Alterations- und Desintegrationstest (MADT), der Antigentest, der Polymerasetest oder der DNS-Hybridisierungstest, Abhilfe schaffen.

Im MADT wird die Wirksamkeit in einem elektronenmikroskopischen Verfahren überprüft. Dazu wird das Virus zum Beispiel aus einer mit Desinfektionsmitteln behandelten Serumprobe isoliert, gereinigt, konzentriert und mikroskopiert. Die zunehmende Degeneration von Viruspartikeln in Abhängigkeit von der Einwirkungszeit und/ oder Anwendungskonzentration der Mittel läßt sich in verschiedene Stadien der Alteration und Desintegration einteilen. Der Test wurde bei seiner Entwicklung durch Tierversuche an Schimpansen verifiziert.

Ähnlich wird beim Polymerasetest nach der Behandlung einer Serumprobe die Funktion der Hepatitis B-Virus DNS-Polymerase in einem Enzymtest überprüft. Das Enzym befindet sich im Inneren des Viruspartikels und verliert bei einer erfolgreichen Zerstörung seine Aktivität.

Der Antigentest beruht zumeist auf einem käuflichen System für die Bestimmung von Oberflächenantigenen, wie er in der Hepatitis-B-Routinediagnostik eingesetzt wird. Hier wird der Effekt auf ein isoliertes Oberflächenantigen geprüft, welches offenbar für die Virusadsorption und $\mathrm{Pe}$ netration notwendig ist.

Der Hybridisierungstest schließlich prüft die Unversehrtheit der Virus-DNS und erlaubt dadurch Rückschlüsse auf den Erfolg der Desinfektionsmaßnahme. 
Um dem Praktiker bei der Auswahl viruzider Desinfektionsmittel zu helfen, sei zuletzt auf die unterschiedlichen Listungen hingewiesen: Die Desinfektionsmittelliste des Bundesgesundheitsamts macht mit einer Eintragung in den Wirkungsbereich B eine Aussage zur Viruzidie der eingetragenen Handelsprodukte und Desinfektionsverfahren. Die DVG erstellt für den Veterinärbereich eine separate Liste, in der eine Aussage zur Teil- bzw. Vollviruzidie der Mittel aufgenommen werden kann. Die DVV plant die Einführung .von Zertifikaten für jedes Handelsprodukt und von der Deutschen Gesellschaft für Hygiene und Mikrobiologie (DGHM) soll künftig eine Viruzidieaussage zu Instrumentendesinfektionsmitteln in der DGHM-Desinfektionsmittelliste möglich sein.

\section{Schlußbetrachtung}

Wie bei kaum einer-anderen Gruppe von Krankheitserregern hängt bei Viren der Erfolg chemischer Desinfektionsmaßnahmen vom Bautyp und Umweltfaktoren, ebenso von deren epidemiologischen Eigenarten und vom Desinfektionsmittel selbst ab. Die Wirkungsweise des Desinfektionsmittels kann schließlich durch eine Anzahl weiterer Faktoren beeinflußt werden.

Zwar werden im Hinblick auf Viruswirksamkeit mitunter Kompromisse gemacht, vor allem überall dort, wo die Bakterienwirksamkeit im Vordergrund zu stehen scheint, für den Einsatz in der medizinischen Praxis ist jedoch zumindest eine Teilviruzidie gegen behüllte Viren, insbesondere gegen HIV und HBV, häufig jedoch eine volle Viruzidie der Präparate zu fordern. Bei der Vielzahl der möglichen Einflußfaktoren ist es notwendig, jedes Desinfektionsmittel und Verfahren, insbesondere aber solche für kritische Bereiche, durch eine Vielzahl von Untersuchungen experimentell abzusichern, denn im Gegensatz zur weitverbreiteten Ansicht erweisen sich Viren unter natürlichen Bedingungen meist als ausgesprochen umwelt- und chemikalienresistent.

\section{Anschrift der Verfasser:}

Dr. Friedrich von Rheinbaben

Laboratorien für Virologie, Henkel KGaA

jo Postfach 1100

; ; 4000 Düsseldorf 1

Prof. Dr. M. H. Wolff

Institut für Mikrobiologie und Virologoie

der Universität Witten/Herdecke

Stockumer Str. 10

5810 Witten-Annen
Schrifttum:

1. BARLOW, D. F.: The aerosol stability of a strain of foot-and-mouth disease virus and the effects on stability of precipitation with ammonium sulphate, methanol or polyethylene glycol. J. Gen. Virol. 15, 17-24 (1972).

2. BERNINGER, M., HAMMER, M., HAYER, B., GERIN, J. L.: An assay for the detection of DNA gnome of hepatitis B virus in serum. J. Med. Virol. 9, 57-68 (1982).

3. BROWN, F.: Unconventional viruses and the central nervous system. Br. Med. J. 295, 347-348 (1987).

4. BROWN, P., GIBBS, C. J., GAJDUSEK, D. C.: Transmission of Creutzfeldt-Jakob disease from formalin-fixed, paraffin-embedded human brain tissue. N. Engl. J. Med. 315, $1614-1615$ (1986).

5. BUNDESGESUNDHEITSAMT: Richtlinie des Bundesgesundheitsamtes und der Vereinigung zur Bekämpfung der Viruskrankheiten zur Prüfung von chemischen Desinfektionsmitteln auf Wirksamkeit gegen Viren. Bundesgesundhbl. 25, 397-398 (1982).

6. Deutsche Veterinärmedizinische Gesellschaft e. V.: Richtlinien für die Prüfung chemischer Desinfektionsmittel. Gießen (1984).

7. DICKGIESSER, N., PRIMAVESI, C. A.: Zur viruziden Wirkung von ausgewählten in der VII. Liste der DGHM empfohlenen Instrumentendesinfektionsmittein auf die Bakteriophagen T4, 01 und f2. Hyg. + Med. 13, 407-412 (1988).

8. DIRINGER, H.: Unkonventionelle Viruskrankheiten. Bundesgesundhbl. 5, 187-194 (1990).

9. DREES, O.: Über den Wirkungsmechanismus viruzider Desinfektionsmittel. Zbl. Bakt. Hyg., Ref. 201, 358-359 (1966).

10. EGGENSPERGER, H.: Desinfektionswirkstoffe und ihre Wirkungsmechanismen. Dtsch. Apoth. Ztg. 113, 785-791 (1973).

11. EGGERS, H. J.: Experiments on antiviral activity of hand disinfectants. Some theoretical and practical considerations. Zbl. Bakt. 273, 36-51 (1990).

12. FRAENKEL-CONRAT, H., OLCOIT, H. S.: The reaction of formaldehyde with proteins. V. Crosslinking between amino and amide or guanidyl groups. Z. Am. chem. Soc., 70, 2673 (1948).

13. FRAENKEL-CONRAT, H.: Reaction of nucleic acid with formaldehyde. Biochim. Biophys. Acta 15, 308 (1954).

14. GORDON, M. P.: Role of protein in the inactivation of viruses by ultraviolet radiation. Aging, Carcinog., Radiat. Biol., (Proc. Int. Conf.), 105-122 (1976).

15. GOTTARDI, W.: Über die Reaktion von Chlor, Brom, Jod und einigen N-Chlor und $\mathrm{N}$-Bromverbindungen mit Pepton in wãssriger Lösung. Zbl. Bakt. Hyg., I. Abt. Orig. B 162, 384-388 (1976)

16. HAAS, R., THOMSSEN, R., DOSTAL, V., RUSCHMANN, E.: Untersuchungen zum Mechanismus der Formaldehydinaktivierung von Polioviren. Arch. Ges. Virusforsch. 9 470-483 (1960).

17. KIRCHHOFF, H.: Wirkungsmechanismus chemischer Desinfektionsmittel, I. Allgemeiner Reaktionsablauf. Gesundheitswesen und Desinfektion 66, 125-130 (1977).

meiner Reaktionsablauf. Gesundheitswesen und Desinfektion 66, 125-130 (1977).

18. KIRCHHOFF, H.: Wirkungsmechanismus chemischer Desinfektionsmittel, II. Spe-
zielle Reaktionsabläufe bei einzelnen Desinfektionsmitteln. Gesundheitswesen und zielle Reaktionsabläufe bei ein

19. KLEIN, M., DEFOREST, A.: Principles of viral inactivation. In: Block, S. S.: Disinfection sterilization and preservation. Verlag Lea \& Fibinger, Philadelphia. 3. Aufl. 422-434 (1983).

20. KUWERT, E.: Probleme der Virusdesinfektion. Internist 26, 73-82 (1985).

21. KUWERT, E., THRAENHART, O., DERMIETZEL, R., SCHEIERMANN, N.: Zur Hepatitis-B-Wirksamkeit und Hepatoviruzidie von Desinfektionsverfahren auf der Grundlage des MADT. 4. Aufl. mhp-Verlag, Wiesbaden (1983).

22. LEMBKE, J., TEUBER, M.: Inaktivierung von Bakteriophagen durch Desinfektionsmittel. Dtsch. Molkereizeitung 102, 580-587 (1981).

23. MAHNEL, H.: Virusdesinfektion in Labor und tierârztlicher Praxis. Tierärztliche Praxis 12, 117-130 (1984).

24. MAYR, A.: Die Bedeutung tierpathogener Viren für den Menschen. Hyg. + Med. 12, 311-314 (1987).

25. MOLDENHAUER, D.: Quantitative evaluation of the effects of disinfectants against viruses in suspension experiments. Zbl. Bakt. Hyg., I. Abt. Orig. B 179, 544-554 (1984). 26. NATH, N. FANG, C. T. DODD, R. Y.: Inactivation of DNA-polymerase associated with hepatitis B-Virus. J. Med. Virol. 10, 131-140 (1982)

27. NODA N. WATANABE, M. YAMADA, F. FUJIMOTO, S.: Virucidal activity of alco27. NODA, N., WATANABE, M., YAMADA, F., FUJIMOTO, S.: Virucidal activity of alco-
hols. Virucidal efficiency of alcohols against viruses in liquid phase. J. Jap. Ass. Infect. hols. Virucidal efficiency of alcohols against viruses in liquid phase. J. Jap. Ass. Infect. Dis. 55, 355-366 (1981).

28. POLLARD, E. C.: Theory of the physical means of the inactivation of viruses. Ann. N. Y. Acad. Sci. 83, 654-660 (1960).

29. PRUSINER, S. B., McKINLEY, M. P.: Prions, novel infections pathogens causing Scrapie and Creutzfeldt-Jakob Disease. Academic Press, London (1987). 30. ROGGENDORF, M.: Hepatitis-C-Virus. Dtsch. med. Wschr. 115, 352-354 (1990). 31. ROSENBERG, R. M., WHITE, C. L., BROWN, P., GAJDUSEK, D. C., VOLPE, I. J., POSNER I DYCK P. J. Precautions in handling tissues, fluids and other contaminated materials from patients with documented or suspected Creutzfeldt-Jakob Disease. materials from patients with

32. SATTAR, S. A., IJATZ, M. K.: Spread of viral infections by aerosols. CRC Critical Re32. SATTAR, S. A., IJATZ, M. K.: Spread of viral intect
views in Environmental Control 17, 89-131 (1987).

33. SATTAR, S. A., SPRINGTHORPE, V. S., KARIM, Y., LORO, P.: Chemical disinfection of non-porous inanimate surfaces experimentally contaminated with four human pathogenic viruses. Epidem. Inf. 102, 493-505 (1989).

34. SCHULZE, E.: Die virologische Überwachung der Trinkwasserqualität, eine Ūbersicht. Zbl. Mikrobiol. 145, 135-143 (1990):

35. SCHUSTER. J. M., HOLLINGER, B., DREES̄MAN, G. R., MELNICK, J. L.: Immunologicl and biophyscal alteration of hepatitis $B$ virus antigens by sodium hypochlorite gicel and biophysical alreration of hepatis B virus antige

disinfection. Appl. Environ. Microbiol. 42, 762-767 (1981). Wirkung einiger PVP-Jod-Ver36. SPORKENBACH, J.: Uber die fehlende inaktivierende Wirkung einiger PVP-Jod-Verbindungen gegenüber Poliomyelitis- und Adenoviren. Hyg. + Med. 5, 357-362 (1980). 37. STEINMANN, J., BOSE, A., ARNOLD, W.: HBV-Wirksamkeit von chemische
fektionsmitteln im DNS-Polymerase-Test. Hyg. + Med. 10, 255-258 (1985).

38. THURMAN, R. B., GERBA, C.: The molecular mechanisms of viral inactivation by water desinfectants. Advances Appl. Microbiol. 33, 75-106 (1988).

39. TYLER, R., AY IFFE, G. A. J., BRADLEY, C.: Virucidal activity of disinfectants: studies with the poliovitus. J. Hosp. Infect. 15, 339-345 (1990).

40. ZESCH, A.: Desinfektionsmittel als zugelassene Arneimittel. Hyg. + Med. 14, 135-140 (1989). 


\title{
Diskussionsvorschlag für ein einheitliches Referenzmethodenkonzept auf der Grundlage der "Richtlinien der Bundesärztekammer zur Qualitäts- sicherung in medizinischen Laboratorien"
}

Discussion Paper for an uniform Reference Method Concept on the Basis of the "Guidelines of the Medical Society of Germany for the Quality Assurance in Medical Laboratories"

D. Stöckl, H. Reinauer, W. Appel, A. v. Klein-Wisenberg

\begin{abstract}
Zusammenfassung:
Seit der Einführung der neuen Richtlinien der Bundesärztekammer zur Qualitätssicherung in medizinischen Laboratorien hat sich vor allem eine intensive Diskussion über die Durchführbarkeit des dort geforderten Referenzmethodenkonzeptes entwickelt. Die vorliegende Arbeit versucht, Beurteilungskriterien für Referenzmethodenwerte zu entwickeln. Es werden einheitliche Qualitätskriterien für Referenzmethoden beschrieben, vor allem werden Vorgaben für die Richtigkeit und die Präzision dieser Methoden diskutiert. Dabei wird berücksichtigt: der Stand der Literatur, die heutigen analytischen Möglichkeiten und die Durchführbarkeit der Methoden.
\end{abstract}

Schlüsse/wörter:

Externe Qualitätskontrolle - Richtlinien - Referenzmethoden

\begin{abstract}
Summary:
Since the introduction of the Guidelines on Quality Assurance in Medical Laboratories of the Medical Society of Germany, an intense discussion evolved especially on the practicability of the reference method concept. This paper aims to develop criteria for the evaluation of reference method values. It describes uniform quality criteria for reference methods, with special emphasis on their accuracy and precision. They are discussed in view of the scientific literature, the todays analytical potential, and the practicability of the methods.
\end{abstract}

Keywords:

External quality control - guidelines - reference methods

\section{Einleitung}

Die neuen Richtlinien der Bundesärztekammer zur Qualitätssicherung in medizinischen Laboratorien (RiliBäk) [1] sind seit März 1988 gültig.

Ein wesentlicher Teil dieser Richtlinien ist es, die Richtigkeitskontrolle in der internen und externen Qualitätskontrolle nicht wie früher mit methodenabhängigen Sollwerten, sondern mit Referenzmethodenwerten durchzuführen. Diese Referenzmethodenwerte werden mit Hilfe von Referenzmethoden ermittelt.

In Abschnitt 1.1 Rangfolge der Analysenmethoden Punkt (3) der Richtlinien wird eine Referenzmèthode wie folgt definiert:

(3) Eine Referenzmethode liefert einen Referenzmethodenwert; seine Abweichung vom richtigen Wert ist im Hinblick auf die medizinischen Erfordernisse vernachlässigbar klein. Die Richtigkeit einer Referenzmethode wird geprüft, entweder
- durch Vergleich mit Definitiven Methoden (sofern vorhanden)

- durch Verwendung eines primären Standardmaterials (Kalibriermaterial)

- durch Verwiendung eines vereinbarten Standardmaterials.

Die Referenzmethode wird also in eine Hierarchie von Analysenmethoden eingeordnet. Sie hat nicht den Rang der besten zur Zeit verfügbaren Analysenmethode für einen bestimmten Analyten (Definitive Methode), sondern sie soll sich an den medizinischen Erfordernissen des entsprechenden Analyten ausrichten. Sie soll sich aber auch an den analytischen Möglichkeiten orientieren, um die bestmögliche praktikable Richtigkeit zu erreichen. Die medizinischen Erfordernisse, die die Qualitätsanforderungen an die jeweilige Analysenmethode bestimmen, werden im allgemeinen aus der Streubreite des Normalbereiches abgeleitet (vgl. hierzu die Ausführungen im Vorwort der Richtlinien) [2]. 


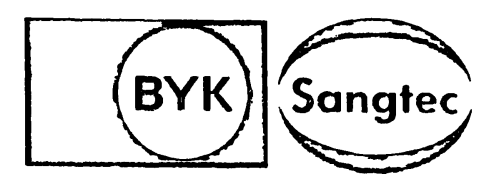

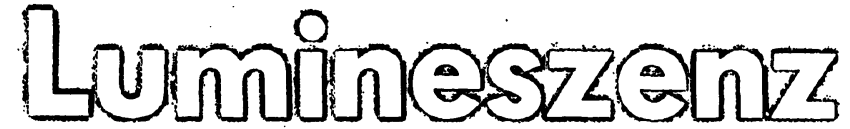 hor einen Nonen}
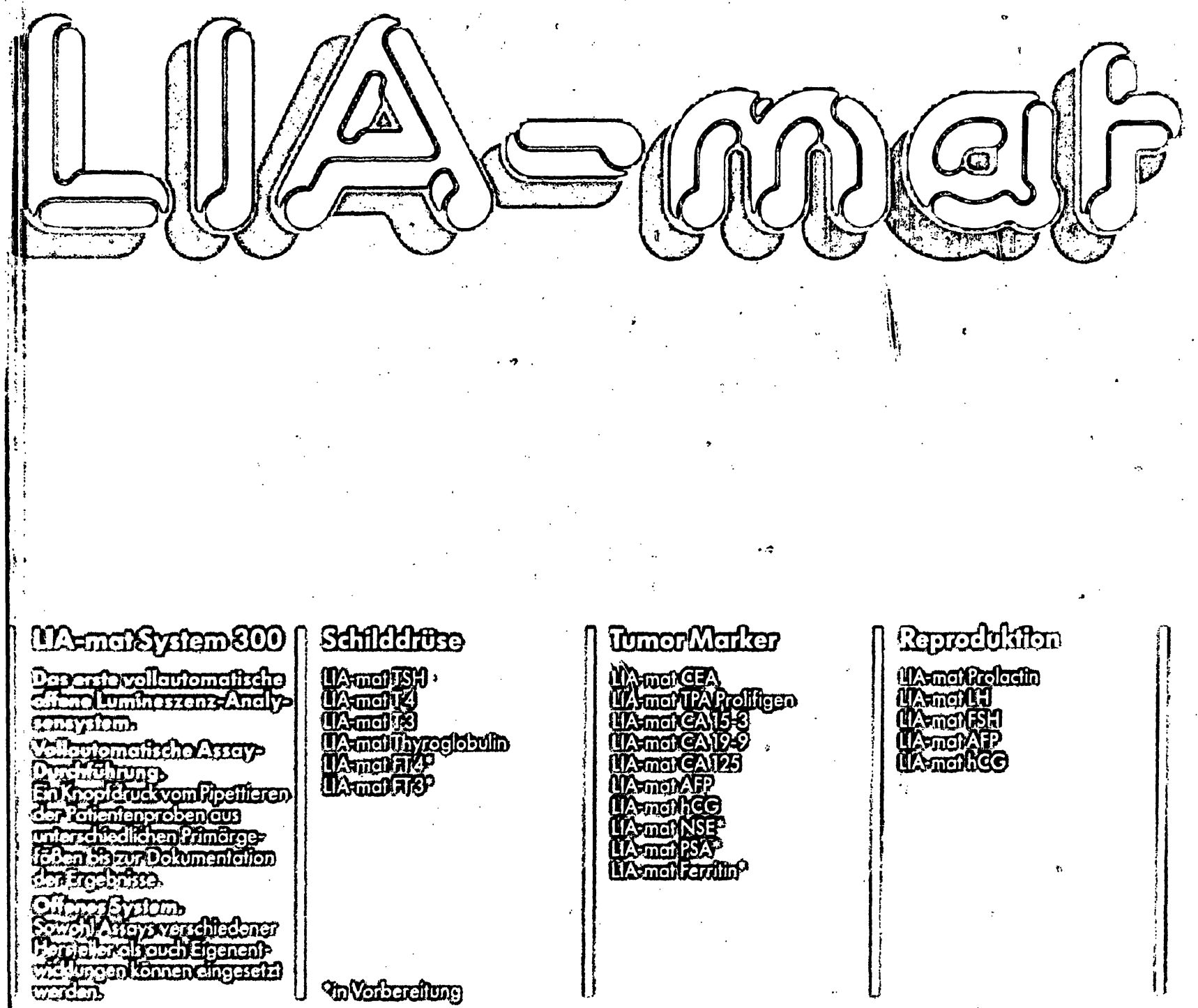


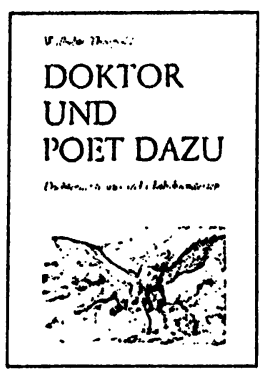

Literaturpreis 1988 der Bundesärztekammer WILLELLM THEOPOLD Doktor und Poet dazu

Dichterärzte aus sechs Jahrhunderten 428 Seiten, geb. $39,80 \mathrm{DM}, 2$. Aufl. ISBN 3-87409-032-9

$\rightarrow 0$

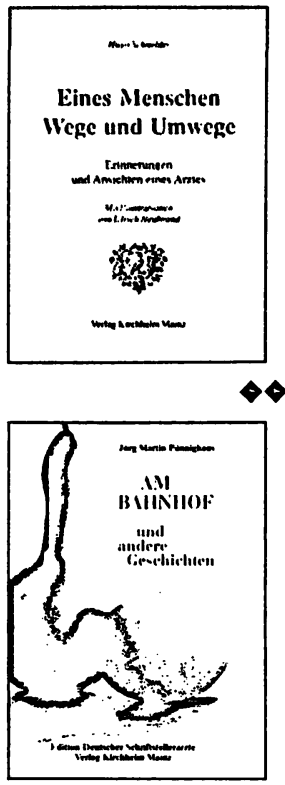

HUGO SCHNEIDER

Eines Menschen Wege und Umwege

208 Seiten,

Leineneinband. $29,80 D M$

ISBN 3-87409-040-X

$\diamond \diamond \bullet$

JÖRG MARTIN PÖNNIGHAUS

Am Bahnhof und andere Geschichten

144 Seiten,

Leineneinband,

24,80 DM

ISBN 3-87409-042-6<smiles></smiles>

Verlag Kirchheim, Postrach 2524, 6500 Mainz

\section{Bestellschein}

Ich bestelle folgende Titel (bitte ankreuzen):

$\square$ Doktor und Poet dazu

$\square$ Weggefährten

$39,80 \mathrm{DM}$

$\square$ Der Schwimmgürtel

$\square$ Hinter Bremsspur und Blaulicht

列,

$\square$ Trotz Rollstuhl und Sozialdienst

$\square$ C'est la vie

$\square$ Alfred Döblin

$\square$ Sterne über fernen Ländern

$\square$ Die Porzellanpendüle

$\square$ Der Schneemann

$\square$ vorwiegend heiter

$\square$ Eines Menschen Wege und Umwege

Am Bahnhof und andere Geschichten

$15,80 \mathrm{DM}$

$16,80 \mathrm{DM}$

$16,80 \mathrm{DM}$

$19,80 \mathrm{DM}$

$18,00 \mathrm{DM}$

$24,80 \mathrm{DM}$

$29,80 \mathrm{DM}$

$19,80 \mathrm{DM}$

$19,80 \mathrm{DM}$

$29,80 \mathrm{DM}$

$24,80 \mathrm{DM}$

Name

Straße

PLZ

Ort

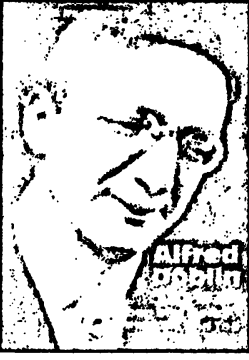

HARALD NEUMANN Alfred Döblin

Leben und Werk

Krankheit und Tod

112 Seiten, Broschur. 18,00 DM

ISBN 3-87409.031-0

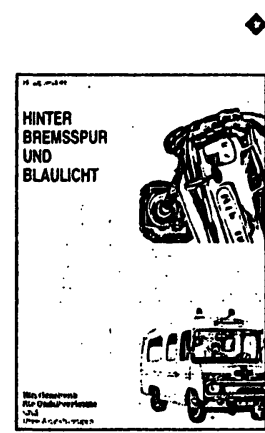

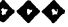

HANS SPIECKER

Hinter

Bremsspur und Blaulicht

Ein Geschenk für

Unfallverletzte und inre Angehörigen

69 Seiten, 16,80 DM ISBN 3-87409-033-7

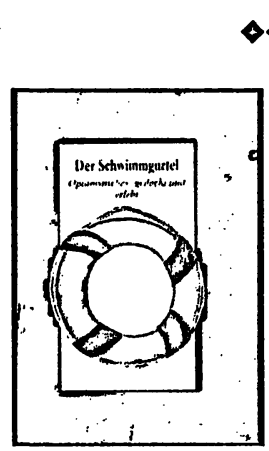

$\diamond \diamond \diamond$

HELMUT KAATZSCH

Der

Schwimmgürtel

Optimistisches,

gedacht und erlebt

40 Seiten, Broschur,

15,80 DM

ISBN 3-87409-027-2

$\diamond \diamond \diamond$

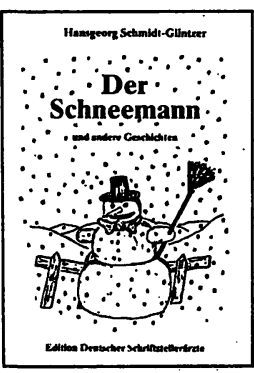

HANSGEORG

SCHMIDT-GLINTZER

Der

Schneemann

und andere

Geschichten

92 Seiten

Leineneinband,

$19,80 D M$

ISBN 3-87409-037-X

$\Delta \bullet$

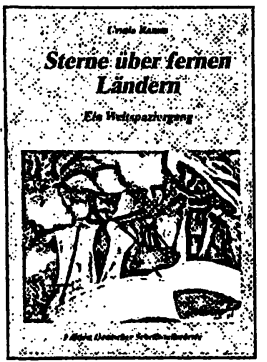

Literaturpreis 1990 der Bundesärztekammer URSULA RAMM Sterne über. fernen Ländern Ein Weltspaziergang 148 Seiten, Leineneinband, 24,80 DM ISBN 3-87409-035-3

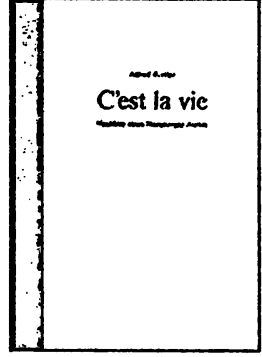

ALFRED ROTTLER C'est la vie

Nachlese eines Nürnberger Arztes 108 Seiten. geb., 19,80 DM

ISBN 3-87409-034-5

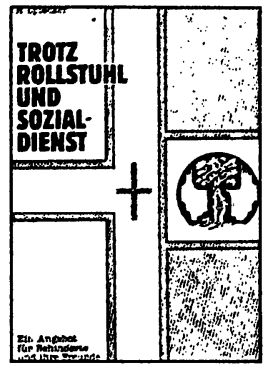

HANS SPIECKER

Trotz Rollstuhl und Sozialdiens

Ein Angebot für Behinderte und inre Freunde

64 Seiten, Broschur, 16,80 DM

ISBN 3-87409-029-5

\section{$\diamond \diamond$}

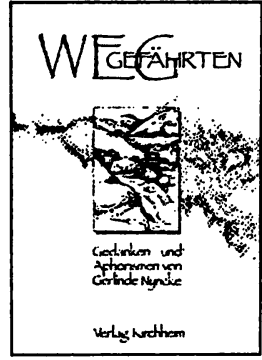

GERLINDE NYNCKE Weggefährten Gedanken und Aphorismen

48 Seiten, Leinenein band, 16,80DM, 2. A L ISBN 3-87409-043-4

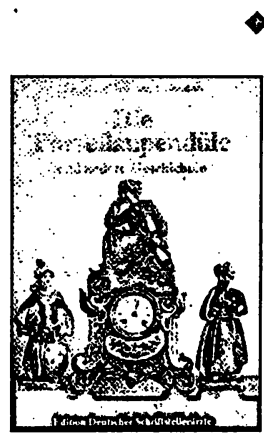

$\rightarrow$

WOLFGANG LOHMANN

Die Porzellanpendüle

und andere Geschichten

224 Seiten,

Leineneinband,

$29,80 D M$

ISBN 3-87409-036-

$\leftrightarrow \bullet$

vorwiegend

he iter

aus dem Leben eines

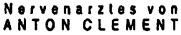

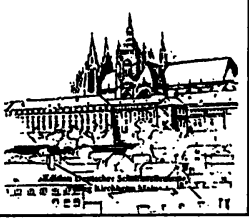

ANTON CLEMENT vorwiegend heiter

aus dem Lebèn eines Nervenarzte :

88 Seiten,

Leineneinband,

19,80 DM

ISBN 3-87409-039: 
Wer erhebt nun eine bestimmte Analysenmethode in den Rang einer Referenzmethode? Die Richtlinien führen dazu in Abschnitt 2.2.3 Punkt (3) aus:

Die Bundesärztekammer . . . legt im Einvernehmen mit der Physikalisch-Technischen Bundesanstalt fest, wie Referenzmethodenwerte zu ermitteln ... sind.

Die Bundesärztekammer delegiert aber ihre Befugnis an die beiden Referenzinstitutionen (RiliBäk Anlage 3):

- Zentrale Referenzinstitution der Deutschen Gesellschaft für Klinische Chemie e. V.

- Institut für Standardisierung und Dokumentation im Medizinischen Laboratorium e. V. (INSTAND e. V.)

Im Abschnitt 3.1.1 der Richtlinien heißt es nämlich:

(1) Referenzmethoden nach Abschnitt 1.1 sollen unter der Aufsicht der Wissenschaftlich-Medizinischen Fachgesellschaften aufgebaut und/oder geprüft oder von ihnen anerkannt oder empfohlen worden sein. Sie sind in Anlage 3 aufgeführt.

Für INSTAND, als eine der beiden Referenzinstitutionen, ergab sich daher die Aufgabe, ein Konzept für den Aufbau von Referenzmethoden zu entwickeln, denn die Richtlinien enthalten explizit keine Forderungen über z. B. die Richtigkeit oder die Unpräzision von Referenzmethoden. Aus den in Anlage 2 der Richtlinien aufgeführten Referenzmethoden bzw. Definitiven Methoden läßt sich ebenfalls kein einheitliches Beurteilungskriterium ableiten.

In den Richtlinien werden die Referenzmethoden deutlich von den Definitiven Methoden unterschieden (vgl. Abschnitt 1.1). Es wird deshalb zuerst untersucht, ob die in Anlage 2 der Richtlinien angeführte Literatur ebenfalls diesen Unterschied widerspiegelt. Als Unterscheidungskriterien sollen dabei die Unrichtigkeit und der Variationskoeffizient (Vk) der Methoden herangezogen werden. In Tabelle 1 sind die Literaturwerte für die Unrichtigkeit und den Vk einer Definitiven Methode und einer Referenzmethode für die Analyte Glukose, Harnsäure und Kreatinin aufgeführt.

Vergleicht man diese Werte, dann kann kein Unterschied zwischen den Definitiven und den Referenzmethoden festgestellt werden. Die Vk's der Referenzmethoden liegen sogar unter denen der Definitiven Methoden. In der Literatur werden also oft die Begriffe Definitive Methode und Referenzmethode für analytische Methoden mit den gleichen Zuverlässigkeitskritierien verwandt. Außerdem gibt es für den gleichen Analyten Referenzmethoden von sehr unterschiedlicher Güte, zum Beispiel bei Harnsäure, eine Referenzmethode hat einen Vk von 0,4 bis $0,7 \%$ [7], die andere einen $V_{k}$ von 1,5 bis $2,7 \%$ [9].

Auch die veröffentlichten Werte für die Richtigkeit von Referenzmethoden (meist als prozentuale Abweichung vom

Tab. 1: Richtigkeit und Vk von Definitiven Methoden und Referenzmethoden für die Analyte Glukose, Harnsäure und Kreatinin (vgl. Richtlinien, Anlage 2)

\begin{tabular}{lcccc}
\hline Analyt & $\begin{array}{c}\text { Definitive Methode } \\
\text { Vk (\%) }\end{array}$ & $\begin{array}{c}\text { Richtigkeit (\%) } \\
\text { (abgeschätzt) }\end{array}$ & $\begin{array}{c}\text { Referenzmethode } \\
\text { Vk (\%) }\end{array}$ & $\begin{array}{c}\text { Richtigkeit }=\Delta \\
\text { (\%) Definit. Meth. }\end{array}$ \\
\hline $\begin{array}{l}\text { Glukose } \\
\text { Harnsäure }\end{array}$ & 1 & $>1[3]$ & $0,4-0,9$ & $\pm 0[6]$ \\
Kreatinin & $0,6-1,1$ & $\begin{array}{c}\text { "hoch, weil } \\
\text { ID/MS" [4] } \\
\text { choch, weil } \\
\text { iD/MS" [5] }\end{array}$ & $0,4-0,7$ & $-0,6[7]$ \\
\hline
\end{tabular}

Definitiven Wert) bieten kein einheitliches Bild (vgl. Tabelle 2). Viele Referenzmethoden von Analyten mit hohen Anforderungen an die Meßgenauigkeit (kleine "maximal zulässige relative Meßabweichungen vom Lageparameter") weisen eine größere Unrichtigkeit auf als Analyte mit weniger strengen Anforderungen (vergleiche Calcium [10], Magnesium [11] und Lithium [12] mit Glukose [6], Harnsäure [7] und Kreatinin [8] in Tabelle 2).

Zusammenfassend kann daher festgestellt werden, daß es bisher kein einheitliches Referenzmethodenkonzept gibt. Im folgenden soll daher auf den Grundlagen der Richtlinien der Bundesärztekammer für die Qualitätssicherung in medizinischen Laboratorien ein solches Konzept entwickelt werden.

Dieses Konzept will folgende Kriterien berücksichtigen: 1. die unterschiedlichen medizinischen Erfordernisse für die verschiedenen Analyte (siehe Anlage 1 der Richtlinien)

2. den Stand der Analytik anhand der Literatur (vgl. Anlage 2 der Richtlinien)

3. das primäre Ziel der Referenzmethoden: Kontrollmaterialien für die interne und die externe Qualitätskontrolle zur Verfügung zu stellen.

\section{Überlegungen über die Richtigkeit von Referenzmethoden}

Die folgenden Überlegungen orientieren sich an den medizinischen Erfordernissen für die Routinemethoden, die in den „maximal zulässigen relativen Meßabweichungen vom Lageparameter" der verschiedenen Analyte in Anlage 1 der Richtlinien ausgedrückt sind. Eine Natrium-Bestimmung z. B. muß eine wesentlich größere Präzision und Richtigkeit aufweisen als eine Testosteron-Bestimmung. Wenn also für die Routinemethoden, in Abhängigkeit von den einzelnen Analyten, unterschiedliche Bewertungskriterien hinsichtlich ihrer Präzision und Richtigkeit geschaffen werden, wird vorgeschlagen, die Referenzmethoden entsprechend anzupassen.

Die Referenzmethode für die Bestimmung von Natrium muß dann also eine höhere Richtigkeit aufweisen als z. B. die Referenzmethode für die Bestimmung von Glukose. Eine erste Orientierung über die Unrichtigkeiten von Referenzmethoden sollen einige Daten aus der Literatur in Anlage 2 liefern.

Vergleicht man in Tabelle 2 die Unrichtigkeit der publizierten Referenzmethoden für Calcium [10], Magnesium [11] und Lithium [12] und deren „maximal zulässige relative Meßabweichung vom Lageparameter" aus Anlage 1,

\section{)}

Tab. 2: "Maximal zulässige relative Meßabweichung vom Lageparameter" (vgl. Richtlinien Anlage 1) und Richtigkeit von publizierten Referenzmethoden (vgl. Richtlinien Anlage 2)

\begin{tabular}{lcc}
\hline Analyt & $\mid \backslash \begin{array}{c}\text { „Max. zul. rel. Meßabw. } \\
\text { v. Lagepar.“ (Richtl.) (\%) }\end{array}$ & $\begin{array}{c}\text { Richtigkeit }=\Delta \\
(\%)\end{array}$ \\
\hline Calcium & 10 & $\pm 2[10]$ \\
Magnesium & 12 & $-1,6[11]$ \\
Lithium & 12 & $-2,3[12]$ \\
Glukose & 15 & $\pm 0[6]$ \\
Harnsäure & 18 & $-0,6[7]$ \\
Kreatinin & 18 & $-0,5[8]$ \\
\hline
\end{tabular}


dann schlagen wir hieraus als maximale Unrichtigkeit einer Referenzmethode den Faktor $0,2 \times$ "maximal zulässige relative Meßabweichung vom Lageparameter" vor.

Man kann das Problem auch unter einem anderen $\mathrm{Ge}$ sichtspunkt betrachten: Referenzmethoden sollen Richtigkeitsvorgaben für die interne Richtigkeitskontrolle und für die externe Qualitätskontrolle liefern. Eine Unrichtigkeit dieses Referenzmethodenwertes diskriminiert nun einen gewissen Prozentsatz von Ringversuchsteilnehmern (angenommen wird eine Gaußverteilung der Teilnehmerwerte; es wird der $+1-3 s$-Bereich betrachtet; ein falscher Zielwert ergibt dann einen falschen $+/-3 s$-Bereich). In Tabelle 3 ist der Prozentsatz der diskriminierten Ringversuchsteilnehmer in Abhängigkeit vom Grad der Unrichtigkeit des Referenzmethodenwertes dargestellt.

Hat der Referenzmethodenwert eine Unrichtigkeit von z. B. $0,2 \times$ der „maximal zulässigen relativen Meßabweichung vom Lageparameter", dann werden $0,57 \%$ der Teilnehmer diskriminiert. Dies wird für vertretbar gehalten.

Aus beiden Überlegungen heraus schlagen wir vor:

- eine Referenzmethode darf eine maximale Unrichtigkeit von 0,2 $\times$ der "maximal zulässigen relativen Meßabweichung vom Lageparameter" der Richtlinien haben. Diese Regel soll aber nicht rein schematisch angewandt werden, je nach dem Stand der analytischen Möglichkeiten soll bei höheren Werten strenger verfahren werden. Für die Referenzmethoden der Hormone wird deshalb z. B. eine maximale Unrichtigkeit von $4 \%$ (der Faktor ist hierbei ca. 0,12 ) vorgeschlagen (vgl. Tabelle 5).

\section{Überlegungen über den Vk einer Referenzmethode}

Der Diskussion über den Vk einer Referenzmethode sollen folgende Überlegungen vorangestellt werden. Ein Referenzmethodenwert ist $i$. a. ein Mittelwert aus einer Serie von Messungen. Dieser Mittelwert $(\mu)$ hat einen systematischen Fehler, der unabhängig ist vom Vk der Me-

Tab. 3: Diskriminierung von Teilnehmern der Externen Qualitätskontrolle in Abhängigkeit von der Unrichtigkeit des Referenzmethodenwertes

\begin{tabular}{cc}
\hline $\begin{array}{c}\text { Abweichung in } X \times \text { „Max. } \\
\text { zul. rel. Meßabw. v. Lagep." }\end{array}$ & $\begin{array}{c}\text { \% diskriminierte } \\
\text { Teilnehmer }\end{array}$ \\
\hline 0 & 0 \\
0,1 & 0,12 \\
0,2 & 0,57 \\
0,3 & 1,52 \\
\hline
\end{tabular}

Tab. 4: Vergleich der vorgeschlagenen Referenz-Vk's und veröffentlichten Literaturwerten aus Anlage 2 für einige referenzmethodenpflichtige Analyte

\begin{tabular}{lcc}
\hline Analyt & $\begin{array}{c}\text { Referenz-Vk (\%) } \\
\text { (Vorschlag) }\end{array}$ & Literatur-Vk (\%) \\
\hline Natrium & 1 & $0,5[13]$ \\
Chlorid & 1 & $1[14]$ \\
Kalium & 1,5 & $1,3[15]$ \\
Harnsäure & 2 & $1,5-2,7[9]$ \\
Cholesterin & 2 & $1,3-2,8 .[16]$ \\
\hline
\end{tabular}

thode und von der Anzahl der Messungen, und einen zufälligen Fehler, der vom Vk und der Anzahl der Messungen bestimmt wird. Bei $n=6$ bzw. $n=12$ Messungen hat der Mittelwert $(\mu)$ beim zweiseitigen $95 \%$-Vertrauensbereich $(\alpha=0,05)$ folgende statistische Unsicherheiten:

a) 6 Messungen: $n=6$

$\mu_{1}=\bar{x}_{1} \pm t_{(5)} \times \frac{\sigma_{1}}{\sqrt{6}} t$-Wert $\left(n=6 ; \frac{2 \alpha}{2}=0,05\right)=2,57$

b) 12 Messungen: $n=12$

$\mu_{2}=\bar{x}_{2} \pm t_{(11)} \times \frac{\sigma_{2}}{\sqrt{12}} t-$ Wert $\left(n=12 ; \frac{2 \alpha}{2}=0,05\right)=2,20$

Damit ist:

$\mu_{1}=\bar{x}_{1} \pm \frac{2,57}{\sqrt{6}} \times \sigma_{1}=\bar{x}_{1} \pm 1,05 \times \sigma_{1}$

$\mu_{2}=\bar{x}_{2} \pm \frac{2,20}{\sqrt{12}} \times \sigma_{2}=\bar{x}_{2} \pm 0,635 \times \sigma_{2}$

Daraus folgt $u$. a., wenn $\sigma_{1}=0,635 / 1,05 \sigma_{2}=0,605 \sigma_{2}$ ist, dann haben die beiden Mittelwerte $\mu_{1}$ und $\mu_{2}$ den gleichen $95 \%$-Vertrauensbereich.

Die statistische Unsicherheit eines Mittelwertes beim $95 \%$-Vertrauensbereich beträgt zum Beispiel $\pm 2,1 \%$ bei $n=6$ und $V k 2 \%$, sie beträgt $\pm 0,64 \%$ bei $n=12$ und $V k$ $1 \%$. Der angestrebte Vk beim Aufbau einer Referenzmethode wird aus diesen Überlegungen auch von der Anzahl der wirtschaftlich durchführbaren Messungen bestimmt werden (die Werte in Tabelle 5 sollen als Beispiel

Tab. 5: "Maximal zul. relative Meßabweichung vom Lageparameter" der Routinemethoden und maximale Unrichtigkeit und Unpräzision von Referenzmethoden für die in Anlage 1 der Richtlinien aufgeführten Analyte mit referenzmethodenpflichtigem Lageparameter

\begin{tabular}{lccccc}
\hline Analyt & $\mathbf{1}$ & $\mathbf{2}$ & $\mathbf{3}$ & $\mathbf{4}$ & $\mathbf{5}$ \\
\hline Chlorid & 6 & 1,2 & 1 & 0,64 (a) & 0,56 \\
Natrium & 6 & 1,2 & 1 & 0,64 (a) & 0,56 \\
Kalium & 8 & 1,6 & 1,5 & 0,95 (a) & 0,65 \\
Eiweiß & 9 & 1,8 & 1,5 & 0,95 (a) & 0,85 \\
Calcium & 10 & 2,0 & 2 & 1,27 (a) & 0,73 \\
Magnesium & 12 & 2,4 & 2 & 1,27 (a) & 1,13 \\
Lithium & 12 & 2,4 & 2 & 1,27 (a) & 1,13 \\
Glukose & 15 & 3 & 2 & 2,10 (b) & 0,90 \\
Harnsäure & 18 & 3 & 2 & 2,10 (b) & 0,90 \\
Kreatinin & 18 & 3 & 2 & 2,10 (b) & 0,90 \\
Cholesterin & 18 & 3 & 2 & $2,10(\mathrm{~b})$ & 0,90 \\
Triglyceride & 21 & 3 & 2 & $2,10(\mathrm{~b})$ & 0,90 \\
Theophyllin & 24 & 4 & 3 & $3,14(\mathrm{~b})$ & 0,86 \\
Thyroxin & 24 & 4 & 3 & 3,14 (b) & 0,86 \\
Aldosteron & 30 & 4 & 3 & 3,14 (b) & 0,86 \\
Cortisol & 33 & 4 & 3 & 3,14 (b) & 0,86 \\
Östradiol & 33 & 4 & 3 & 3,14 (b) & 0,86 \\
Progesteron & 33 & 4 & 3 & 3,14 (b) & 0,86 \\
Testosteron & 45 & 4 & 3 & 3,14 (b) & 0,86 \\
\hline
\end{tabular}

1.t "Maximal zulässige relative Meßabweichung vom Lageparameter" $(\%)$ der Routi- ; nemethoden (vgl. Anlage 1 der Richtlinien)

2.: Vorschlag für die maximal zulässige Unrichtigkeit (\%) der Referenzmethode

3.: Vorschlag für einen Vk $(\%)$ der Referenzmethode

4.: Statistische Unisicherheit $(\%)$ des Referenzmethodenwertes bei (a) $n=12$, (b) $n=6$

5.: Maximal zulässiger systematischer Fehler $(\%)$ der Referenzmethode (Spalte 2-4) 
dienen für die erforderlichen Vk's bei $n=6$ bzw. $n=12$, um die oben gestellten Richtigkeitsforderungen zu erfül(en). Je nach systematischem Fehler der Methode erzielbarem Vk und der Anzahl der wirtschaftlich durchführbaren Messungen, können die Werte für $V k$ und $n$ aber auch andere Beträge annehmen. Im Mittel erhält man im obigen Beispiel einen "Referenz-Vk" von 0,6 × "maximal zulässige relative zufällige Meßabweichung" (vgl. Richtlinien Anlage 1). In Tabelle 4 sind die Literatur-Vk's und die vorgeschlagenen Referenz-Vk's für einige Analyte angegeben. Der Vergleich zeigt, daß die vorgeschlagenen Variationskoeffizienten im Einklang mit den Literaturwerten stehen.

In Tabelle 5 sind nun alle oben angeführten Kriterien für eine Referenzmethode zusammengefaßt: 1. Die „Maximal zulässige relative Meßabweichung vom Lageparameter" nach Anlage 1 der Richtlinien; 2. Die maximale erlaubte Unrichtigkeit der Referenzmethoden; 3. Der Vorschlag für einen VK dẹr Referenzmethoden; 4. Die statistische Unsicherheit des Referenzmethodenwertes bei $n=$ 6 bzw. $n=12$ Messungen; 5 . Die maximale systematische Unrichtigkeit der Referenzmethoden (Spalte 2-4).

\section{Zusammenfassung}

Das vorgestellte Konzept beruht auf folgender Prämisse der medizinischen Analytik: Die Anforderungen an die Zuverlässigkeit der Messungen wird nicht so hoch wie technisch möglich angesetzt, sondern sie richtet sich nach den „medizinischen Erfordernissen”. Aufgrund dieser Prämisse wurden in den Richtlinien für die Qualitätssicherung in medizinischen Laboratorien Vorgaben für die Unpräzision und die maximale Unrichtigkeit für $\mathrm{Be}$ stimmungsmethoden der dort aufgeführten Analyte angegeben. An diesen Vorgaben orientieren sich die Forderungen für die Richtigkeit und die Unipräzision von Referenzmethoden. Der Vorteil dieses Konzeptes ist seine Einheitlichkeit, seine Kriterien gelten für Natrium genauso wie z. B. für Testosteron. Sollten in Zukunft die medizinischen Erfordernisse anders festgelegt werden, dann würden auch die Referenzmethoden automatisch neu strukituriert. Neu hinzukommende Analyte lassen sich problemlos in das vorhandene Konzept einordnen. Das Konzept ist praktikabel, d. h., die Forderungen sind erfüllbar und die Analytik kann in einem vertretbaren Zeit-KostenRahmen durchgeführt werden.

\section{Anschriften der Verfasser:}

Dr. Dietmar Stöckl

INSTAND e. V.,

Johannes-Weyer-Straße 1

4000 Düsseldorf 1

\section{Hans Reinauer}

Universität Düsseldorf

Diabetesforschungsinstitut

Auf'm Hennekamp 65

4000 Düsseldorf 1

\section{Wolter Appel}

St. Vincentius Krankenhaus

Südendstraße 32

7500 Karlsruhe 1

Albert von Klein-Wisenberg

Am Lindacker 3

7800 Freiburg

\section{Probenvorbereitung mit Durchblick: Die BAKER Spe-Methode.}

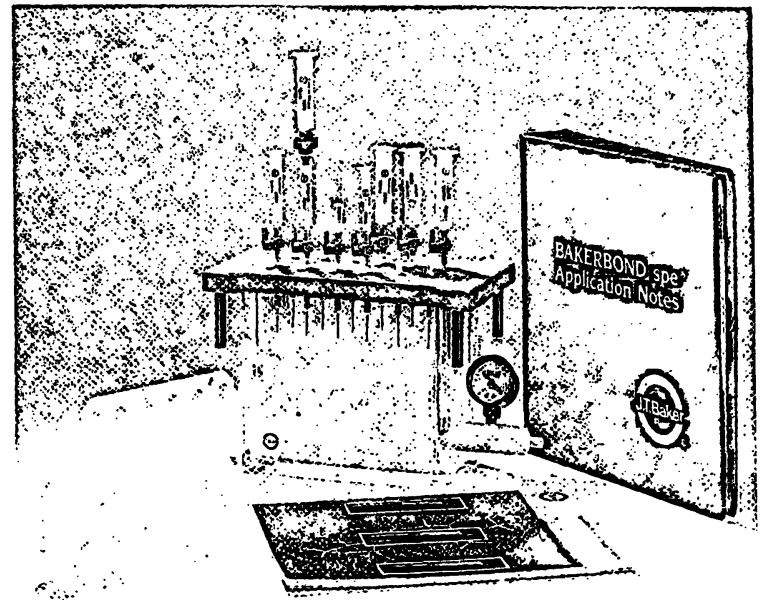

\section{Proben auf einen Streich.}

Probenvorbereitung geht mit der BAKER spe-Methode erfahrungsgemäß schnell, reproduzierbar und wirtschaftlich. Für fast alle Proben gibt es eine geeignete spe-Trennsäule. Diese sind mit analytischen Festphasen gefüllt. Ein umfangreiches Analysenzertifikat liegt jeder Packung bei. Zur MethodenEntwicklung gibt es von Baker kostenlos über 300 Rezepte und Literaturstellen. Die Broschüre „Solid Phase Extraction for Sample Preparation" und einen Sammelband "BAKERBOND spe Application Notes" gibt es beim Bezug eines BAKER spe-Systems zusätzlich. Fordern Sie Unterlagen an. Baker Chemikalien, Postfach 1661, 6080 Groß-Gerau, Telefon (06152) 710378

Schrifttum:

1. Richtlinien der Bundesärztekammer zur Qualitätssicherung in medizinischen Laboratorien. Dt. Ärztebl. 85, A699-A712 (1988).

2. STAMM, D.: Qualitätssicherung der quantitativen Bestimmungen im Laboratorium. Neue Richtlinien der Bundesärztekammer. Dt. Ärztebl. 85, A697-A699 (1988).

3. WHITE, V. E., WELCH, J., SUN, T., SNIEGOSKY, L. T., SCHAFFER, R., HERTZ, H. S. COHEN, A.: The accurate determination of serum glucose by isotope dilution mass spectrometry - two methods. Biomed. Mass Spectrom. 9, 395-405 (1982).

4. SIEKMANN, L.: Determination of uric acid in serum by isotope dilution - mass spectrometry. J. Clin. Chem. Clin. Biochem. 23, 129-135 (1985).

5. SIEKMANN, Determination of creatinine in human serum by isotope dilution mass spectrometry. J. Clin. Chem. Clin. Biochem. 23, 137-144 (1985).

mass spectrometry. J. Clin. Chem. Clin. Biochem. 23, 137-144 (1985). . SCHUMANN, G., BUTTNE़R, J.: Determination of glucose in reference materials by isotope dilution - mass spectrometry. Fresenius Z. Anal. Chem. 330, 424-425 (1988). 7. KOCK, R., DELLOUX, B., TILLMANNS, U., GREILING, H.: A candidate reference method for the determination of uric acid in serum based on high performance liquid chromatography, compared with an isotope dilution gas chromatography - mass spectrometer method. J. Clin. Chem. Clin. Biochem. 27, 157-162 (1989).

8. SCHUMANN, G., BÜTTNER, J.: A candidate reference method for creatinine with HPLC. Fresenius Z. Anal. Chem. 324, 279-280 (1986).

9. DUNCAN, P. H. GOCHMAN, N. COOPER, T, SMITH, E., BAYSE, D.: A candidate reference method for uric acid in serum. I. Optimization and evaluation. Clin. Chem. 28, 284-290 (1982).

10. CALI, J.P. MANDEL, J., MOORE, L., YOUNG, D. S.: A reference method for the determination of calcium in serum. NBS Spec. Public. 260-63.

11. KÜLPMANN, ${ }^{2}$ BUCHHOIZ R DRYSSEN, C., RUSCHKE, D.: A comparison of reference method values for calcium, lithium and magnesium with method dependent assigned values. J. Clin. Chem. Clin. Biochem. 27, 631-637 (1989).

12. VELAPOLDI, R. A. PAULE, R. C., SCHAFFER, R., MANDEL, J., MACHLAN, L. A., GARNER, E. L., RAINS, T. C.: A reference method for the determination of lithium in serum. NBS Spec. Public. 260- 69.

13. VELAPOLDI, R. A., PAULE, R. C., SCHAFFER, R., MANDEL, J., MOODY, J. R.: A reforence method for the determination of sodium in serum. NBS Spec. Public. 260-60. 14. VELAPOLOI R A PAULE, R. C SCHAFFER, R. MANDEL, J, MURPHY, T J. GRAMLICH, J. W. A roference method for the determination of chloride in serum. NBS Spec. Public. 260-67.

NBS Spec. Public. 260-67. 15. VELAPOLDI, R. A, PAULE, R. C., SCHAFFER, R., MANDEL, J., MACHLAN, L. A., NBS Spec. Public. 260-63.

16. SIEKMANN, L, HÜSKES, K. P., BREUER, H.: Determination of cholesterol in serum using mass fragmentography - a reference method in clinical chemistry. Fresenius $Z$. Anal. Chem. 279, 145-146 (1976).

Lab.med. 15: 339 (1991) 


\title{
Vorschläge zur mikrobiologischen Verarbeitung von Untersuchungsmaterialien aus dem unteren Respirationstrakt
}

\author{
Proposals for Microbiological Processing of Lower Respiratory Tract Specimens
}

Helga Hollandt, R. Marre

Institut für Medizinische Mikrobiologie der Medizinischen Universität zu Lübeck (Direktor Prof. Dr. W. Henkel)

\section{Zusammenfassung:}

Die Aussagekraft von Befunden bei der mikrobiologischen Diagnostik von unteren Atemwegsinfektionen wird von der Qualität der Probe und der Methode der Weiterverarbeitung im Labor bestimmt. Wegen des hohen Anteils an Bakterien der physiologischen oder durch nosokomiale Einflüsse veränderten Standortflora im Untersuchungsmaterial gelingt der Nachweis potentieller Pneumonieerreger nur, wenn quantitative Faktoren bei der Materialverarbeitung und Befundinterpretation berücksichtigt werden. Bei Sputumproben kann eine Zahl von mehr als 25 Leukozyten pro Blickfeld (Vergrößerung 100x) als Hinweis auf eine bakterielle Infektion gewertet werden und ist eine Entscheidungshilfe bei der Weiterverarbeitung von fakultativ pulmopathogenen Erregern. Die bronchoalveoläre Lavage rechtfertigt einen größeren Aufwand zur Ermittlung einer exakten Keimzahlbestimmung und einer quantitativen Analyse des Zellbildes mit dem Anteil von Granulozyten, Lymphozyten und Alveolarmakrophagen. Ein an unserem Institut bewährtes Untersuchungsschema wird vorgestellt. Danach können Keimzahlen von mehr als $10 \% / \mathrm{ml}$ Lavage als signifikant angesehen werden. Dies korreliert mit dem entzündlich veränderten Zellbild und der Klinik.

Schlüsselwörter:

Pneumonie - Sputum - bronchoalveoläre Lavage

\section{Summary:}

The value of cultures of lower respiratory tract specimens is dependant on the quality of the specimen and the methods used for processing of the specimen in the clinical microbiological laboratory. Detection of respiratory tract pathogens is largely affected by the microflora normally present in the throat and the frequency of nosocomial acquisition of potential pathogens and thus warrants the use of quantitative methods for processing of the specimens. In the case of sputa, more than 25 leukocytes/field in a gram stain (magnification 100x) are suggestive of a bacterial infection and helps to decide on species identification and susceptibility testing of potential pulmopathogenic bacteria. The bronchoalveolar lavage justifies the higher costs for the exact determination of bacterial counts and the proportion of granulocytes, lymphocytes, and alveolar macrophages in the lavage. A procedure which is established at our institution is presented here. According to this, bacterial counts of more than $10^{4} / \mathrm{ml}$ lavage can be regarded as significant and correlate well with the cellular composition of the specimen and the clinical diagnosis of pneumonia.

Keywords:

pneumonia - bronchoalveolar lavage - sputum cultures

\section{Einführung}

Die Aussagekraft der Befunde bei der mikrobiologischen Diagnose von Infektionen ist abhängig von der Qualität der Untersuchungsmaterialien, bestimmt durch deren Gewinnung und Transport, und von den Aufbereitungsmethoden, die in den einzelnen Laboratorien eingesetzt werden. Der Erregernachweis bei Atemwegsinfektionen wird dadurch erschwert, daß die Untersuchungsmaterialien in Abhängigkeit von der Materialgewinnung Begleitkeime der normalen bzw. nosokomialveränderten Standortflora enthalten. Die in unserem Institut praktizierten Aufarbeitungsmethoden basieren teilweise auf den in der Literatur vorliegenden Empfehlungen (Cumitech $7 \mathrm{~A}$,
1987 [1] und DGHM-Empfehlungen, 1980 [2]), die von uns aus den Erfahrungen der Laborpraxis heraus weiterentwickelt wurden. Dadurch ist es bei angemessenem Arbeitsaufwand möglich, eine Vielzahl von Proben standardisiert zu verarbeiten. Unsere Aufarbeitungsmethode bei Sputum, Tracheal-, Bronchial- und Absaugsekreten gestattet einen semiquantitativen Erregernachweis. Der Erregernachweis aus der Bronchoalveolären Lavage (BAL) erfolgt quantitativ $(3,4)$. Da aktualisierte Empfehlungen für, die mikrobiologische Diagnose von Infektionen der tieferen Atemwege entsprechend den DGHM-Richtlinien noch nicht verfügbar sind und DIN-Vorschriften sich derzeit im Stadium der Bearbeitung befinden, soll die an unserem Institut bewährte Methodik zur Diskussion gestellt werden. 


\section{Semiquantitativer Erregernachweis}

Die Untersuchung umfaßt die makroskopische Beurteilung, die Vorbehandlung, die Mikroskopie und die Kultur der Sekretproben sowie deren Weiterverarbeitung.

\subsection{Makroskopische Beurteilung der Untersuchungsmate-} rialien

Sputen, Tracheal-, Bronchial- und Absaugsekrete werden aus den Transportgefäßen in sterile Petrischalen entleert. Die Sekrete werden auf ihre Beschaffenheit nach den folgenden Gesichtspunkten beurteilt: schleimig, eitrig (homogen eitrig, Eiterpartikel), blutig, dünnflüssig, wäßrig, schaumig. Dabei muß auf folgende Fehlermöglichkeiten hingewiesen werden: schleimige, opak aussehende Sekrete, große Sekretmengen, die häufig gelblich erscheinen, "eosinophile" Sekrete und Sekrete mit Fibrin und Zelltrümmern können fälschlich als eitrig angesehen werden.

\subsection{Vorbehandlung der Untersuchungsmaterialien}

Die Verarbeitung der Sekrete erfolgt wegen der Infektionsgefahr in einer Sicherheitswerkbank der Klasse II, da Aerosole bei der Manipulation entstehen können. Schleim- oder Eiterbestandteile werden mit Hilfe von einer oder evtl. auch zwei Ösen (oder sterilen Holzstäben) von der Speichelflüssigkeit abgetrennt und aus der Petrischale in $1 \mathrm{ml} \mathrm{TSB}^{1}$ überführt. Es kommt dabei je nach Partikelgröße zu einer Probenverdünnung von 1:10 bis $1: 100$. Durch den Verdünnungsvorgang werden störende Begleitkeime der normalen wie auch der evtl. nosokomial veränderten Standortflora ausverdünnt, so daß die in höheren Konzentrationen vorliegenden Infektionserreger bei der Bewertung des Anzuchtsversuchs besser erkannt werden (5). Das Untersuchungsmaterial wird durch Schütteln in der mit Glasperlen versetżten TSB homogenisiert. Keime, die in fibrinöses Material eingebettet sind, sollen dadurch aus den Fibringerinnseln herausgelöst werden. Wäßrige Sekrete ohne Schleim- bzw. Eiterbeimengungen werden nicht vorbehandelt. Für die mikroskopische Untersuchung werden nun, ebenfalls aus der Petrischale, solche Schleim- bzw. Eiterpartikel in dünner Schicht auf Objektträger ausgebreitet, deren Aussehen denen der in TSB gelösten vergleichbar ist. Auch im Falle wäßriger Sekrete wird ein mikroskopisches Präparat angefertigt.

1 Die Trypticase Soja Bouillon (TSB) kann im Vorrat hergestellt und kühl aufbewahrt werden. In der Sicherheitswerkbank werden 8-12 Glasperlen und $1 \mathrm{ml}$ TSB in Sputumröhrchen steril abgefüllt und im Kühlschrank bis zum Verbrauch (3-5 Tage) aufgehoben. Vor der Verwendung ist die TSB auf Verkeimung zu überprüfen.

Tab. 1: Anzahl der Zellen/Blickfeld (nach Bartlett, Ryan, Smith et al. [1])

\begin{tabular}{|ccc}
\hline Sputum-Klasse & Leukozyten & Plattenepithelzellen \\
\hline 1 & $<10$ & $>25$ \\
2 & $10-25$ & $>25$ \\
3 & $>25$ & $>25$ \\
4 & $>25$ & $10-25$ \\
5 & $>25$ & $<10$ \\
6 & $<25$ & $<25$ \\
\hline
\end{tabular}

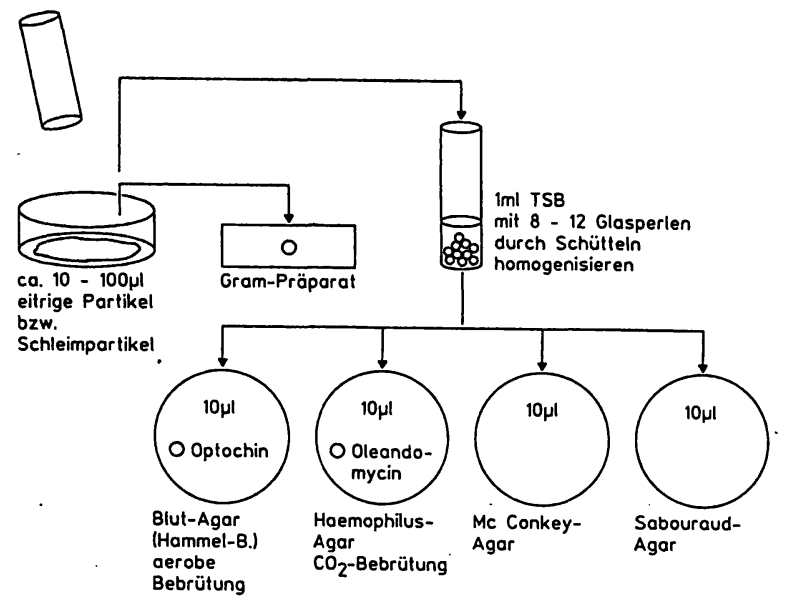

Abb. 1: Aufarbeitung von Sputum, Tracheal-, Bronchial- und Absaugsekret

\subsection{Mikroskopische Untersuchung}

\subsubsection{Sputum: Gramfärbung}

Mit einem Objektiv des Abbildungsmaßstabs $10 \times$ wird bei einer Okularvergrößerung von $8 \times$ bis $10 \times$ das Grampräparat durchmustert und dabei der Anteil von Leukozyten und Plattenepithelien pro Blickfeld abgeschätzt. Es erfolgt eine Einteilung der Sputen in die Klassen 1 bis 6 nach Anzahl der Leukozyten und Plattenepithelien pro Blickfeld (Tab. 1).

Bei 800 - bis 1000 facher Vergrößerung werden nun Bakterien- und Pilzgehalt bestimmt. Sind in Sputumpräparaten bei 100 facher Vergrößerung weniger als 25 Plattenepithelien pro Gesichtsfeld vorhanden, ist das Untersuchungsmaterial für Kulturzwecke geeignet (Klassen 4, 5, 6). Sind außer den Plattenepithelien auch die Leukozyten vermehrt ( $>25 /$ Gesichtsfeld), so sind Kulturen gerechtfertigt (Klaśse 3). Plattenepithelien in großer Menge (> 25/Gesichtsfeld) sind ein Hinweis auf Speichelbeimengungen (Klassen 1, 2). Solche Sputen werden nicht aufgearbeitet. Der Leukozytengehalt im Sputum unterliegt allerdings einer Vielzahl von Einflüssen (Tab. 2). Ein hoher Leukozytenanteil bei fehlendem Nachweis schnell wachsender Mikroorganismen soll auch an Infektionen durch Mykobakterien, Chlamydien und Mykoplasmen denken lassen.

\subsubsection{Tracheal-, Bronchial-, Absaugsekrete: Gramfärbung}

Bei 100facher Vergrößerung ist die Anzahl der Leukozyten und Epithelien pro Blickfeld abzuschätzen. Anschließend erfolgt bei 800 - bis 1000 facher Vergrößerung die Durchmusterung auf mögliche Infektionserreger. Auch bei diesem Material sind für die Bewertung der Leukozytenzahlen die in Tabelle 2 genannten Einflußfaktoren zu berücksichtigen.

Tab. 2: Einflußfaktor für den Leukozytenanteil (2)

\begin{tabular}{|c|c|}
\hline Leukozyten & $\begin{array}{l}\text { tteil } \\
\text { erhöht }\end{array}$ \\
\hline $\begin{array}{l}\text { Zerfall während des Transports, } \\
\text { Zerstörung durch mikrobielle } \\
\text { Enzyme, } \\
\text { Zerstörung durch Speichelenzyme, } \\
\text { Immunsuppression }\end{array}$ & $\begin{array}{l}\text { bakterielle Infektionen, } \\
\text { Tracheostoma, } \\
\text { Intubation, } \\
\text { Asthma bronchiale, } \\
\text { Tumorerkrankungen der } \\
\text { Lunge . . }\end{array}$ \\
\hline
\end{tabular}




\subsection{Kulturelle Untersuchung}

Das Vorgehen bei Anlegen der Kulturen muß sich stets nach den individuellen Gesamtumständen des Krankheitsfalles richten. Die Nährmedien werden so gewählt, daß die Anzucht der zu erwartenden Keime ermöglicht wird (Abb. 1). Dabei müssen die Infomationen, die bei der mikroskopischen Prüfung des Originalpräparates gewonnen wurden, Berücksichtigung finden. Für die Routinediagnostik ist die Beimpfung einer Blutagarplatte und eines Mediums zur Anzucht von Haemophilus ausreichend. Es sind nur feste Kulturmedien erforderlich (Ausnahme Lungenbiopsiematerialien). Eine Anaerobier-Kultivierung erfolgt nur bei Lungenpunktaten, BAL und transtrachealen Aspiraten. Die Nährmedien zur Kultivierung von Haemophilus und Legionellen werden unter $\mathrm{CO}_{2}$-Anreicherung $(3-10 \%) 48$ Stunden, im Falle von Legionellen mindestens 7 Tage bebrütet. Bei besonderer Fragestellung kann der Einsatz weiterer Nährmedien erforderlich werden, z. B. Anzucht von Mykoplasma pneumoniae, Actinomyceten, Nocardien, Pilzen.

Zur Erregeranzucht werden jeweils $10 \mu$ l des homogenisierten Probenmaterials mittels kalibrierter Einmalimpföse auf die entsprechenden festen Nährmedien aufgebracht (Abb. 1) und durch einen 3-Ösenausstrich fraktioniert. Bei dieser Vorgehensweise entspricht $1 \mathrm{KBE}^{2}$ in der 1 . Fraktion des Ausstrichs ca. $10^{3}$ bis $10^{4}$ Keimen $/ \mathrm{ml} \mathrm{Se-}$ kret.

Bei wäßrigen Sekreten werden $10 \mu$ des Patientenmaterials direkt aus der Petrischale auf jeden festen Nährboden verimpft. Da keine Homogenisation in $1 \mathrm{ml}$ TSB erforderlich war, entspricht $1 \mathrm{KBE}$ in der 1. Fraktion des 3Ösenausstrichs ca. $100 \mathrm{Keimen} / \mathrm{ml}$.

Zur Abgrenzung der vergrünenden Streptokokken von Pneumokokken kann ein Optochintestblättchen auf den Blutagar bei der Primärkultur aufgelegt werden. An unserem Institut hat sich ein Haemophilus-Spezialagar (VXAgar) $^{3}$ durchgesetzt, auf dem im Gegensatz zu dem sonst üblichen Kochblutagar ein Teil der störenden Begleitflora nur schwach wächst. Um die Isolierung von Haemophilusarten aus Mischkulturen zusätzlich zu erleichtern, wird ein Oleandomycintestblättchen $(15 \mu \mathrm{g})$ auf den VX-Agar aufgelegt (6).

\subsection{Weiterverarbeitung der Sekrete des unteren Respirationstraktes (Sputum, Tracheal-, Bronchial- und Absaugsekrete)}

Sputen der Klasse 3 erfordern eine Erregeridentifizierung und Resistenzbestimmung, wenn noch Keimwachstum in der dritten Fraktion des 3-Ösenausstrichs vorliegt und es sich um Keimarten handelt, die als Infektionsverursacher in Betracht kommen können. Ebenso werden alle Reinkulturen unabhängig von der Keimzahl aufgearbeitet, wenn der angezüchteten Spezies Krankheitswert beigemessen wird. Bei Sputen der-Klassen 4, 5 und 6 erfolgt eine Identifizierung und Resistenzbestimmung aller angezüchteten

\footnotetext{
$2 \mathrm{KBE}=$ koloniebildende Einheit

3 Zusammensetzung des VX-Agars: ASS-Agar oder DST-Agar IsoVitaleX Hämoglobin Aqua dest. Bei der Zubereitung des Agars ist zu beachten, daß̦ die Zugabe von IsoVitalex und Hämoglobin erst erfolgt, nachdem die beiden anderen Bestandteile für $15 \mathrm{~min}$ bei $121^{\circ} \mathrm{C}$ autoklaviert und auf $60^{\circ} \mathrm{C}$ abgekühlt worden sind.
}

Tab. 3: Weiterverarbeitung von bewachsenen Sputum-Kulturen

\begin{tabular}{ccc}
\hline Sputumklasse & Erregermenge & $\begin{array}{c}\text { Erregeridentifikation } \\
\text { und } \\
\text { Resistenzbestimmung }\end{array}$ \\
\hline 3 & vereinzelt & nein' \\
3 & reichlich & nein' \\
3 & massenhaft & ja \\
$4-6$ & vereinzelt bis massenhaft & ja \\
\hline
\end{tabular}

1 Erregeridentifikation und Resistenzbestimmung bei Vorliegen einer Reinkultur oder bei Wachstum typischer Pneumonieerreger.

Erreger, die als Infektionsauslöser in Frage kommen können (7) (Tab. 3).

Die Feststellung charakteristischer Mikroorganismen in großer Zahl (> 10 Keime/Blickfeld bei 1000facher Vergrößerung) im Grampräparat erleichtert die Entscheidung, ob angezüchtete Keime identifiziert und einer Resistenzbestimmung zugeführt werden sollen. Auch eine wiederholte Anzucht der gleichen Erregerart aus weiteren Sekretproben ist ein Hinweis dafür, daß der Keimart Krankheitswert zugemessen werden kann.

Die Keimzahlangabe erfolgt nach dem Wachstum in den Fraktionen 1 bis 3 des 3-Ösenausstrichs folgendermaßen: vereinzelt (wächst nur in der 1. Fraktion), reichlich (Wachstum auch in der 2. Fraktion), massenhaft (Wachstum in allen 3 Fraktionen).

Die Aufarbeitung der Kulturen aus Tracheal-, Bronchialund Absaugsekreten erfolgt in der Regel wie bei Sputen.

\section{Quantitativer Erregernachweis: Bronchoalveoläre Lavage (BAL) und Mikrobürste}

Die Mikrobürste wird nach Gebrauch vom Untersucher in ein Röhrchen mit $1 \mathrm{ml}$ TSB eingebracht. Diese TSB wird

1

Quontitative Anlage von Kulturen

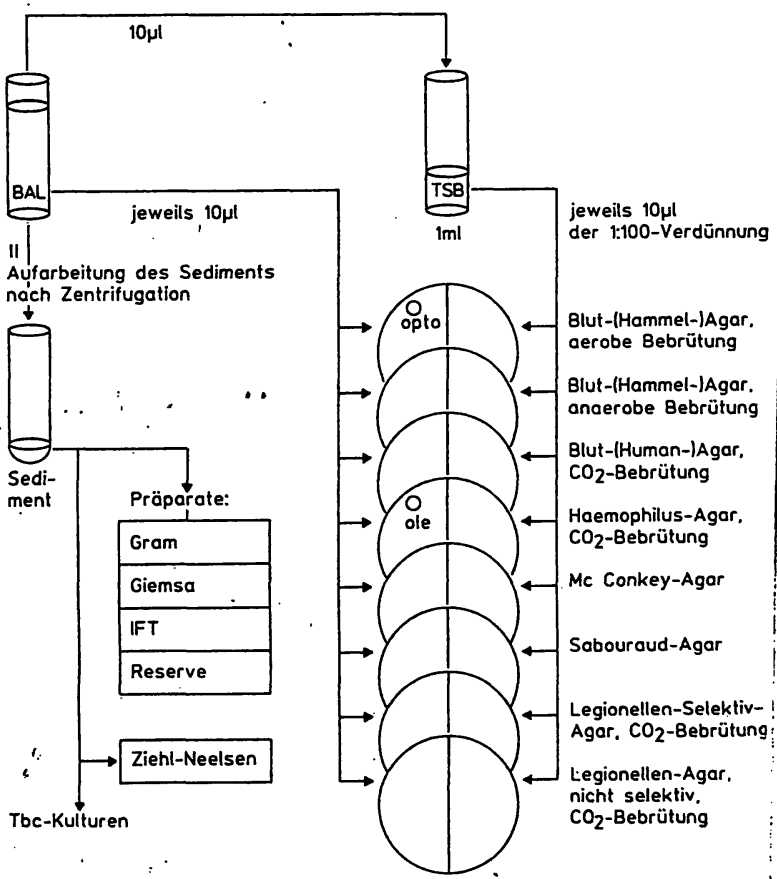

Abb. 2: Bronchoalveoläre Lavage (BAL) 


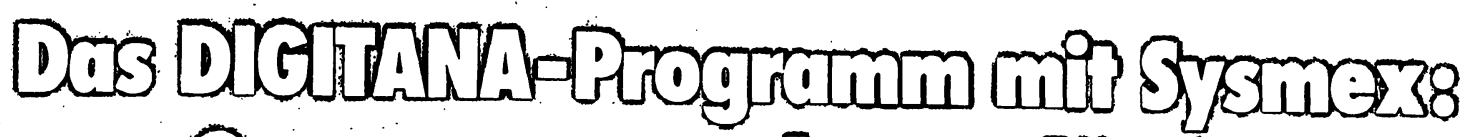

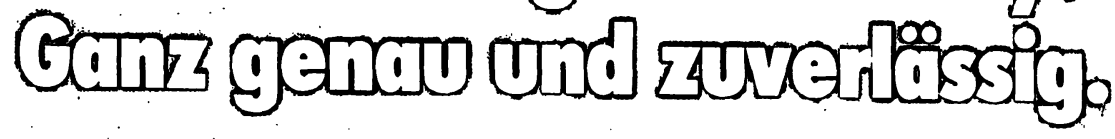

\section{Fïr die grroße Serie:}

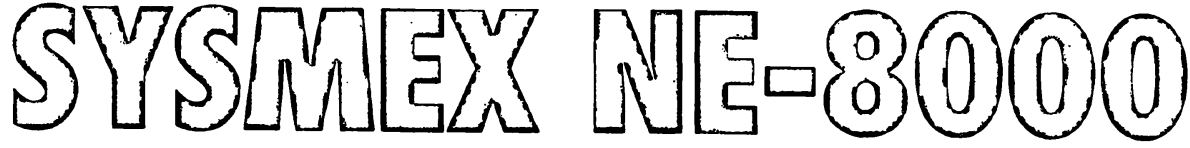

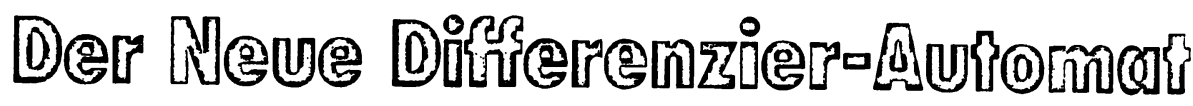

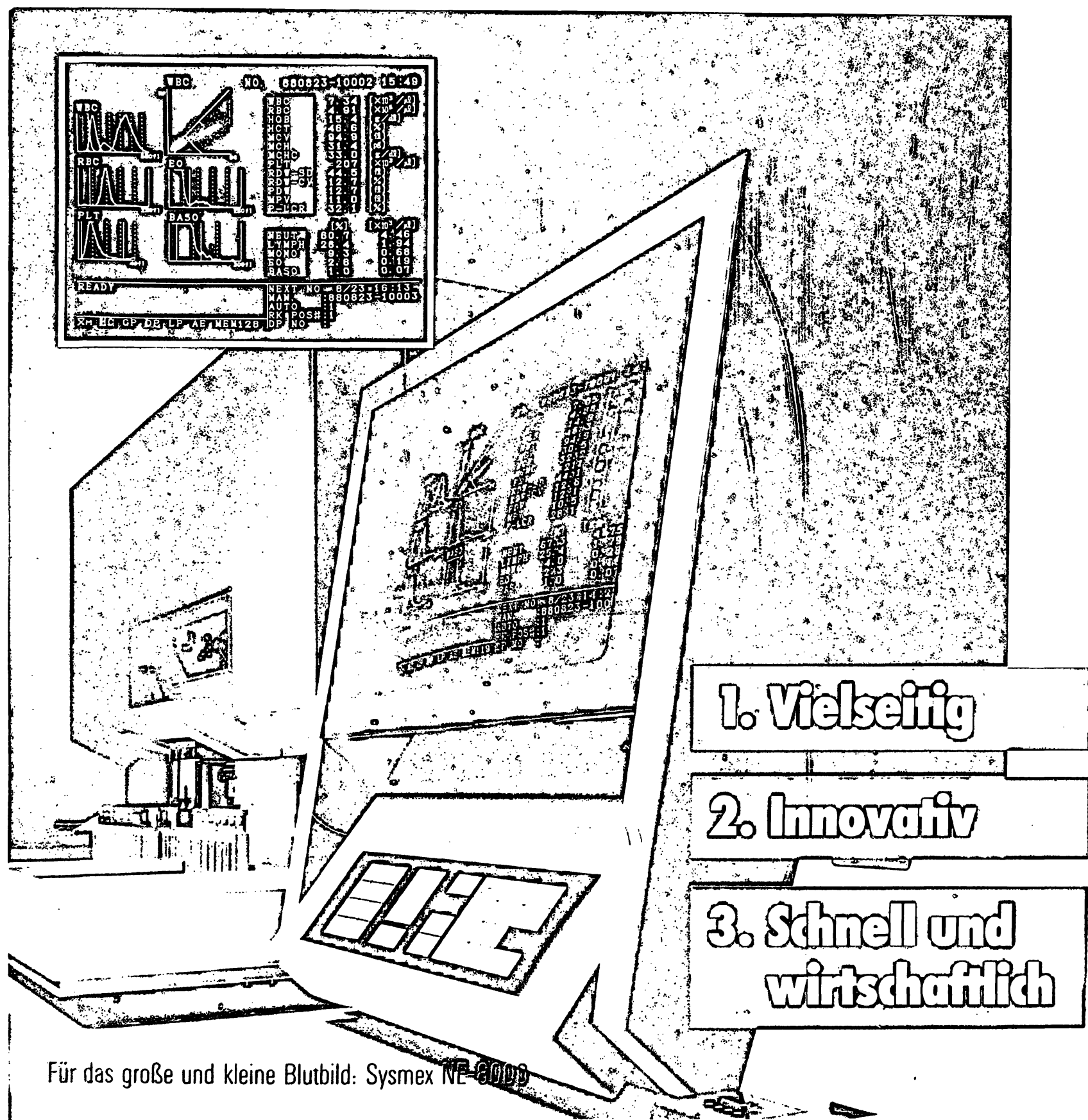




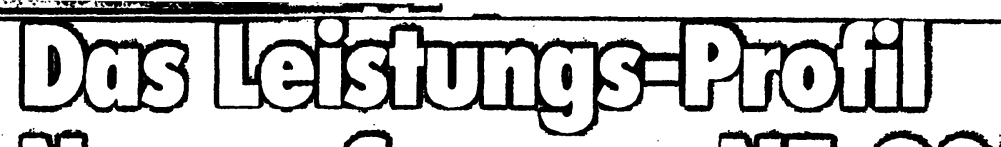

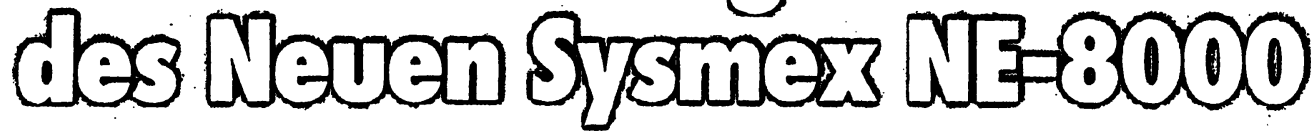

Der Sysmex NE-8000 Differenzier-Automat für das kleine und große Blutbild ist kompromißlos auf Schnelligkeit, Zuverlässigkeit und damit auf äußerste Wirtschaftlichkeit ausgelegt. Sein einzigartiges Leistungsvermögen als Vollautomat beweist er besonders bei der Routine großer Serien.

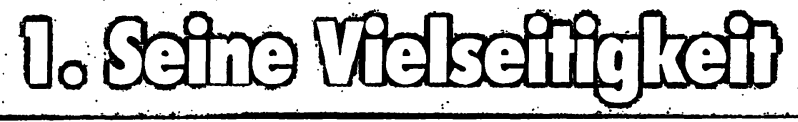

Neben den Basis-Parametern Erythrozyten, Hämoglobin, Hämatokrit, Erythrozyten-Quotienten und Blutplättchen bietet der NE-8000 ein einzigartig vielseitiges Nutzen-Programm : O 3 Kanäle für die Leukozyten-Differenzierung, davon je ein individueller Kanal für Eosinophile und Basophile O Ergebnisausgabe für die 5 Leukozyten-Klassen in absoluten und relativen Werten $O$ Umfangreiches Warnzeichen-System zur Signalisierung unreifer und atypischer Zellen für die schnelle und sichere Identifizierung auffälliger Proben $O$ Entnahme wahlweise aus offenen oder geschlossenen Primär-Gefäßen O Positive Barcode-Proben-Identifikation $O$ Daten-Speicherung und selektiver Aufruf markierter Proben.

Neue Technologien und anwenderfreundliche Details kennzeichnen den NE-8000 als eigen-

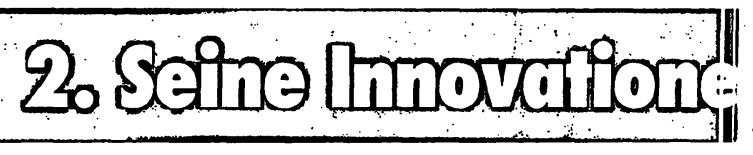
ständige und zukunftsweisende Neu-Entwicklung. Seine Innovationen:

O Neuartige Meßtechnik bei der Leukozyten-Klassifizierung zur differenzierten Signal-Auftrennung. O Neuartige Gestaltung des Lyse-Prozesses für Leukozyten, damit Basos und Eos in eigenen Kanälen selektiv erfaßt werden. $O$ Neuartige Ergebnisausgabe zur schnellen Erfassung und Interpretation aller Informationen eines Befunds. Neben den numerischen Daten enthält die Ergebnisausgabe auch Histogramme und das aussagestarke Scattergramm zur visuellen Sofort-Beurteilung.

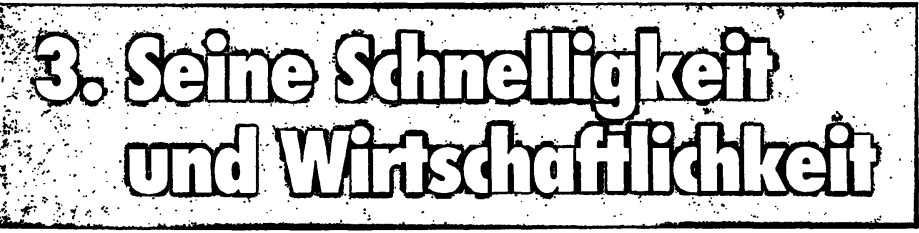

Bestimmte Technologie-Prinzipien und Meßtechniken, die Sysmex Hämatologie-Systemen Weltgeltung verschafft haben, finden sich auch im NE-8000 als Garant für Schnelligkeit, Zuverlässigkeit und damit für Wirtschaftlichkeit.

O Proben-Identifikation und hohe Analysen-Frequenz (120 Proben pro Stunde) $0 \mathrm{Hb}-$ Messung in einem individuellen Kanal $O$ Sysmex-Prinzip der Absolut-Messung 1 Speicherung von 500 kompletten Ergebnissen. 
gleich nach Eingang im Labor auf die gleiche Art wie die BAL kulturell angelegt. Besteht Verdacht auf eine virale Erkrankung im unteren Respirationstrakt, wird ein Teil der BAL abgegossen und für die Virusdiagnostik verwendet.

\subsection{Kulturelle Untersuchung}

Feste Nährmedien werden mit einem Markierungsstift halbiert. Mit einer kalibrierten Impföse werden $10 \mu \mathrm{l} \mathrm{BAL}$ auf eine Nährbodenhälfte ausgestrichen. Die andere Hälfte wird mit $10 \mu \mathrm{l}$ einer in $1 \mathrm{ml}$ TSB auf $1: 100$ verdünnten BAL beimpft (Abb. 2).

\subsection{Mikroskopische Untersuchung}

Nach dem Beimpfen der Kulturplatten wird die restliche BAL zentrifugiert (15 min bei $1000 \mathrm{~g}$ ). Das Sediment wird für die mikroskopischen Präparate und für die Tuberkulosediagnostik verwendet.

Gram- und Giemsapräparate

Bei ca. 100facher Vergrößerung wird das Präparat auf Flimmerepithelzellen durchmustert. Bei ca. $400 f a c h e r$ Vergrößerung wird der Anteil von Makrophagen, Lymphozyten und Granulozyten festgestellt. Im Gegensatz zu bakteriellen Pneumonien, bei denen die neutrophilen Granulozyten überwiegen, ist bei Virusinfektionen der Anteil an Lymphozyten erhöht. Bei ca. 800 - bis 1000 facher VergröBerung findet eine Durchmusterung auf Bakterien und Pilze statt. Mit der Giemsafärbemethode können außerdem Trophozoiten und intrazystische Körperchen von Pneumocystis carinii erfaßt werden (8). Befinden sich Flimmerepithelzellen in größerer Menge im mikroskopischen Präparat der BAL, muß auf Beimengung von Bronchialsekret größeren Ausmaßes geschlossen werden. Dies muß bei der Befundinterpretation Berücksichtigung finden. Solches Material ist für den quantitativen Keimnachweis ungeeignet.

\section{Präparate für den direkten Immunfluoreszenztest (IFT)}

Bei Verdacht auf Legionellen- und Pneumocystis cariniiInfektion können zum Antigennachweis Präparate für den Immunfluoreszenztest vorbereitet werden $(9,10)$.

\section{Präparat für die Ziel-Neelsen-Färbung}

\section{Reservepräparat}

Für den Fall, daß eine zusätzliche Färbung, z. B. GrocottFärbung bei Verdacht auf Pneumocystis carinii Infektion, notwendig werden sollte, ist das Anfertigen eines Reservepräparates zu empfehlen, da das Sediment des Untersuchungsmaterials für die Tuberkulosediagnostik verbraucht wird und somit später nicht mehr zur Verfügung steht.

\subsection{Weiterverarbeitung der Kulturen von BAL und Mikro- bürstenabstrich}

Alle angezüchteten Keime werden quantitativ (Keimzahl/ $\mathrm{ml}$ ) angegeben. Eine Identifizierung und Resistenzbestimmung erfolgt bei Keimen mit einer Keimzahl $>10^{4} / \mathrm{ml}$, allen Reinkulturen und Keimen mit Keimzahlen $<10^{4} / \mathrm{ml}$, wenn sie als Infektionserreger in Frage kommen können (3).

\section{Tab. 4: Entscheidungshilfen für die Befundung}

Weitere Entscheidungshilfen für die Befundung sind:

- Angaben des Einsenders über das Umfeld, aus dem der Patient kommt (Hospital, Ambulanz usw.).

- die klinische Verdachtsdiagnose,

- Art und Dauer der Symptome,

- Hauptlokalisation der Infektion,

- Kenntnisse über vorausgegangene Chemotherapie und/oder immunsuppressive Therapie,

- Kenntnisse über etwaige Grundleiden des Patienten,

- Angaben über Art und Zeitpunkt der Probenentnahme,

- Kenntnisse über Transportdauer und -temperatur der Untersuchungsproben.

\section{Entscheidungshilfen zur Interpretation der Untersuchungsergebnisse}

Die Entscheidung zwischen Infektionserreger, Kontaminations- oder Kolonisationskeim ist häufig schwierig. Neben den beschriebenen, rein mikrobiologischen Weiterverarbeitungs- und Bewertungskriterien der Untersuchungsproben sind die in der Tab. 4 aufgeführten Gesichtspunkte für eine abschließende Beurteilung der Ergebnisse hilfreich.

Schrifttum:

1. BARTLETT, J. G., RYAN, K. J., Smith, T. F., et al.: Laboratory Diagnosis of Lower Respiratory Tract Infections. Cumitech, 7A, 1-18 (1987).

2. Deutschie Gesellschaft für Hygiene und Mikrobiologie, Kommission für Verfahrensrichtlinien: Die mikrobiologische Diagnose von Infektionen der tieferen Atemwege und der Lunge. Zbl. Bakt. Hyg., I. Abt. Orig. A 248, 162-176 (1980).

3. KAHN, F. W., JONES, J. M.: Diagnosing Bacterial Respiratory Infection by Bronchoal3. KAHN, F. W., JONES, J. M.: Diagnosing Bacte
veolar Lavage. J. Infect. Dis. 155, 862 (1987).

4. DALHOFF, K., BRAUN, J., WIESSMANN, K.-J., HOLLANDT, H., MARRE, R.: Bronchos4. DALHOFF, K., BRAUN, J., WIESSMANN, K.-J., HOLLANDT, H., MARRE, R.: Bronchos-
kopische Pneumoniediagnostik mit quantitativer Keimzahibestimmung. Dtsch. med. Wschr. 115, 1459-1465 (1990).

5. FACKLAM, R. R.: Streptococci and Aerococci. Chapter 8, 88-110, in Manual of Clinical Microbiology, Editor E. H. Lennette, ASM, Washington, 3. Edition (1980).

6. HALLMANN, L., BURKHARDT, F.: Klinische Mikrobiologie. Thieme Verlag (1974).

7. SODEMANN, T. M., COLMER, J.: Microbiology of the Respiratory Tract. Laboratory Medicine 14, 96- 102 (1983).

8. Kommission des Bundesgesundheitsamtes Laboratoriumsdiagnostik Intestinaler 8. Kommission des Bundesgesundheitsamtes "Laboratoriumsdiagnostik Laborik der Pneuund Pulmonaler Parasitosen": Empfehlungen zur Laboratorit

mokoniosen. Bundesgesundhbl. 29, Nr. 6, 197-198 (1986).
9. ROTH, A., JANITSCHKE, K.: Anwendbarkeit eines polyklonalen Antiserums fūr den 9. ROTH, A., JANITSCHKE, K.: Anwendbarkeit eines polyklonalen Antiserums für den
immunhistochemischen Nachweis von Pneumocystis carinii in Bronchoalveolar Lavage (BAL). Lab.med. 13, 166 (1989).

10. CREGAN, P., YAMAMOTO. A., LUM, A., et al.: Comparison of Four Methods for Rapid Detection of Pneumocystis carinii in Respiratory Speciems. J. Clin. Microbiol. 28, 2432-2436 (1990).

Korrespondenzanschrift:

Dr. med. Helga Hollandt

Institut für Medizinische Mikrobiologie

der Medizinischen Universität zu Lübeck

Ratzeburger Allee 160

2400 Lübeck 